\title{
Etkinlik ve Etkinliği Belirleyen Faktörler: Havayolu Şirketleri Üzerine Ampirik Bir İnceleme
}

Etkinlik ve Etkinliği Belirleyen Faktörler: Havayolu Şirketleri Üzerine Ampirik Bir İnceleme

\section{Öz}

Bu çalışmanın amacı, havayolu şirketlerinin etkinliklerinin yıllara göre değişimini incelemek ve bu etkinliği belirleyen faktörleri ortaya çıkarmaktır. Bu kapsamda dünyanın farklı bölgelerinde faaliyet gösteren ve verileri 2010-2016 dönemi için süreklilik arz eden 45 havayolu işletmesini ampirik olarak incelenmiştir. Çalışmada havayolu şirketlerinin etkinliklerinin yıllara göre değişimi, veri zarflama analizi kullanılarak araştırılmıştır. Etkinliği belirleyen faktörler ise Tobit regresyon yöntemi aracılığıyla incelenmiştir. Çalışmanın bulguları, analize dâhil edilen on dört havayolu şirketinin ilgili dönemde etkin çıktığını ve diğer havayolu şirketlerine göre daha iyi performansa sahip olduğunu göstermektedir. On havayolu firması ise ilgili dönemlerin tümünde etkin çıkmamıştır. Tobit analiz sonuçları, taşınan toplam yolcu sayısı, doluluk oranı ve Toplam gelir değişkenlerinde meydana gelen pozitif yönlü artışın etkinlik düzeyini arttırdığını göstermektedir.

Anahtar Kelimeler: Veri Zarflama Analizi, Tobit Regresyon, Havayolu, Etkinlik, Verimlilik
Efficieny and Factors Determining Efficiency: An Emprical Review on Airlines

\section{Abstract}

The aim of this study is to examine the yearly changes in the efficiency of airlines and to reveal the factors that determine this efficiency. In this context, 45 airlines operating in different regions of the World, with data for 20102016 period, have been examined empirically. The change in the efficiency of airlines over the years was explored using data envelopment analysis (VZA). The factors determining the efficiency were examined through the Tobit regression method. Findings of the study Show that the fourteen airlines involved in the analysis are efficient in the period concerned and have a better performance than other airlines. Ten airlines were not efficient in all of the related periods. Tobit analysis results show that the positive increase in the number of total passengers carried, load factors and total income variables increases the efficiency level.

Keywords: Data Envelopment Analysis, Tobit Regression, Airway, Airline, Efficiency, Productivity

\section{Giriş}

Ekonomik, sosyal ve kültürel açıdan birçok faydası olan havayolu taşımacılığı sektörü günümüzde en globalleşmiş sektörlerin başında gelmektedir. Teknolojinin gelişmesi ile beraber artan küreselleşme havacılığın daha çok gelişmesine ve yaygınlaşmasına neden olmuştur. Ancak havayolu taşımacılığı sektörüne yönelik yapılan sıkı yasal düzenlemeler hava taşımacılığı sektörünün gelişimini dönem dönem engellemiştir. 1978 yılında Amerika'da yaşanan iç hat serbestleşmesi ile birlikte havayolu işletmeleri, filo yapılarını ve uçuş ağlarını genişletme ve bilet fiyatlarını istedikleri şekilde belirleme imkânı bulmuşlardır (Hooper, 1997: 197). Takip eden yıllarda önce Avrupa'da daha sonra birçok bölge ve ülkede serbestleşme ile ilgili yapılan düzenlemeler havayolu taşımacılığı sektörünü rekabetin daha yoğun yaşandığı bir sektör haline getirmiştir. Bununla birlikte havayolu işletmeleri yoğun rekabet ortamında faaliyetlerini devam ettirebilmek için farklı iş modelleri uygulamakta ve stratejiler geliştirmektedirler.

\footnotetext{
${ }^{1}$ Dr. Öğr. Üyesi, İskenderun Teknik Üniversitesi, Sivil Havacılık Yüksekokulu, Havacılık Yönetimi Bölümü, kasim.kiraci@iste.edu.tr. Yazar ORCID bilgisi: https://orcid.org/0000-0002-2061-171X

${ }^{2}$ Araş. Gör., Anadolu Üniversitesi, Sosyal Bilimler Enstitüsü, Sivil Havacılık Yönetimi Bölümü, veysi-asker@outlook.com. Yazar ORCID bilgisi: https://orcid.org/0000-0002-8969-7822
} 
Tüm sektörlerde olduğu gibi hava taşımacılı̆̆ı sektöründe de finansal ve operasyonel performans yönetimi önemli bir yere sahiptir. Özellikle son zamanlarda yaşanan küresel ekonomik krizlerden sonra, finansal ve operasyonel performans yönetimi havayolu işletmeleri için hayati bir öneme sahip olmuştur. Özellikle artan rekabet ve yakıt fiyatlarının dalgalanması havayolu işletmelerini kontrol edebildikleri maliyetleri en aza indirmek ve operasyonel etkinliklerini arttırmak için farklı stratejiler geliştirmeye zorlamıştır (Vasigh, 2015: 95).

Havayolu işletmelerinin etkinlik ölçümü ile ilgili literatüre bakıldığında filo yapısı, koltuk kapasitesi, arz edilen koltuk kilometre (ASK), ücretli yolcu kilometre (RPK) ve doluluk oranı gibi operasyonel faktörlerin etkinlik ve verimliliğe etkisinin büyük olduğu görülmektedir.

Havayolu işletmelerinin verimlik ve etkinlik ölçümünün yapıldığı çalışmalara bakıldığında genel olarak ekonometrik modellerin, parametrik ve parametrik olmayan yöntemlerin kullanıldığı görülmektedir. Parametrik yöntemlerden Stokastik sınır etkinliği analizinin (Assaf, 2009), parametrik olmayan yöntemlerden ise veri zarflama analizinin yaygın bir biçimde kullanıldığı görülmektedir (Tavassoli vd., 2014; Lee ve Worthington, 2014).

Bu çalışmanın amacı 45 havayolu işletmesinin 2010-2016 yılları arasındaki verimlik ve etkinlik ölçümünün yapılması ve verimliliği etkileyen faktörlerin tespit edilmesidir. Bu açıdan bu çaış̧manın ilerleyen bölümlerinde benzer konularda yapılmış çalışmalar hakkında bilgi verilmiş ve kullanılacak olan VZA ve Tobit regresyon modelinden bahsedilmiştir. Daha sonraki bölümlerde ise kullanılan veriler ve yapılan analizler detaylı bir şekilde anlatılmıştır. Son bölümde ise sonuç ve öneriler sunulmuştur.

\section{Literatür}

Alan yazında farklı sektör ya da kamu kurumlarının veri zarflama analizinin kullanılarak analiz edildiği birçok çalışma yapılmıştır. Bunlar arasında Girginer vd., (2007) Türkiye'de sigortacılık sektöründe faaliyet gösteren firmaları, Yalama ve Sayım (2008) imalat sektöründe faaliyette bulunan şirketleri, Öztürk ve Girginer (2014) Türk tekstil ve hazır giyim firmalarını, Köse vd., (2014) kamu hastanelerinde klinik bölümlerini, Ulucan (2002) isO500 şirketlerini, Özden (2008) Türkiye'deki vakıf üniversitelerini, Kayalıdere ve Kargın (2004) çimento ve tekstil sektörlerinde faaliyet gösteren firmaları veri zarflama analizi yöntemini kullanarak analiz etmiştir.

Veri zarflama analizi havacılık sektöründe faaliyet gösteren firmaların verimlilik ve etkinlik ölçümünde yaygın bir şekilde kullanılmaktadır. VZA hem havalimanı ile ilgili hem de havayolu işletmeleriyle ilgili yapılan etkinlik ölçümü çalışmalarında geniş bir kullanım alanı bulmuştur. Özellikle havayolu işletmelerinin finansal ve operasyonel etkinlik ölçümünde sadece VZA'nın kullanıldığı birçok çalışma bulunmaktadır(Schefczyk, 1993; Good vd., 1995; Capobianco ve Fernandes, 2004; Hong ve Zhang, 2010). Bununla birlikte son dönemlerde havayolu işletmelerinin finansal ve operasyonel performans ölçümünde kullanılan iki aşamalı VZA (Zhu, 2011; Lu vd., 2012; Gramani, 2012) ve ilk aşaması VZA, ikinci aşaması regresyon analizlerinden oluşan çalışmalar bulunmaktadır (Sheraga, 2004; Chiou ve Chen, 2006; Greer, 2009; Bhadra, 2009).

Fethi ve diğerlerinin yapmış olduğu çalışmada, Avrupa'daki havayolu taşımacılığı sektöründe 1980 'lerin sonunda yaşanan liberalleşme ile birlikte havayolu taşımacılığı sektöründe artan rekabetin etkilerinin araştırılması amacı ile Avrupa merkezli 17 havayolu işletmesinin 1991-1995 yıllarına ait etkinlik ölçümü ilk aşamada VZA ile gerçekleştirilmiştir. İkinci aşamada ise çeşitli değişkenlerin verimlilik üzerindeki etkilerinin açıklanabilmesi amacı ile Tobit regresyon modeli uygulanmıştır. Ampirik bulgular, havayolu işletmelerine devlet tarafından sağlanan sübvansiyonların rekabeti olumsuz etkilediği ve bu durumdan olumsuz etkilenen havayolu işletmelerinin 
kapsam ekonomisinden yararlanarak ayakta kalabilecekleri belirtilmiştir. Bu açıdan stratejik ittifaklara üyeliğin, satın alma ve birleşmelerin havayolu işletmeleri tarafından daha fazla tercih edildiğinden bahsedilmiştir (Fethi vd., 2000).

Havayolu işletmelerinin etkinliğinin ölçüldüğü bazı çalışmaların belirli bir ülkede faaliyet gösteren havayolu işletmelerini kapsadığı görülmüştür (Chiou ve Chen, 2006; Lu vd., 2012; Ouellette vd., 2010). Saranga ve Nagpal yapmış oldukları çalışmada, Hindistan'da faaliyet gösteren 13 havayolu işletmesinin 2005-2012 yılları arasındaki finansal ve operasyonel etkinliğini ilk olarak VZA ile ölçmüş sonraki aşamada ise etkinlik üzerinde etkili olan faktörlerin tespit edilmesi amacı ile Tobit regresyon modeli kullanılmıştır. Analiz sonucunda yapısal düzenlemelerle ilgili unsurların havayolu işletmelerinin performansı üzerinde istenmeyen durumlar oluşturduğu tespit edilmiştir. Ayrıca Hindistan'da faaliyet gösteren düşük maliyetli hava taşımacılığı işletmelerinin operasyonel etkinlik oranlarının diğer havayolu işletmelerine göre daha yüksek olduğu görülmüştür (Saranga ve Nagpal, 2016).

Hava taşımacılığı sektöründe verimlilik ve etkinlik ölçümü ile ilgili yapılan bazı çalışmaların dünyanın birçok yerinde faaliyet gösteren havayolu işletmelerini kapsadığı görülmüştür (Arjomandi ve Seufert, 2014; Barbot vd., 2008;). Scheraga, yapmış olduğu çalışmada, dünyanın farklı yerlerinde faaliyet gösteren 38 havayolu işletmesinin 2000 yılındaki finansal ve operasyonel etkinlik ölçümünü VZA aracılığı ile gerçekleştirmiştir. Havayolu işletmelerinin kârlılığını etkileyen faktörlerin tespit edilmesi amacı ile analizin ikinci aşamasında Tobit regresyon modeli kullanılmıştır. Havayolu taşımacılığı sektöründe değişim hızının yüksek olduğu ve havayolu işletmelerinin bu değişime ayak uydurabilmek için finansal yapılarına uygun strateji izlemesi gerektiğinden bahsedilmiştir (Sheraga, 2004). Stratejik kararların havayolu işletmelerinin filo planlamasına olan etkilerinin araştırıldığı çalışmada Merkert ve Hensher, 58 havayolu işletmesinin 2007-2009 yılları arasındaki etkinliğini ilk aşamada veri zarflama analizi ile ölçmüştür. İkinci aşamada ise Tobit regresyon modeli aracılığı ile Havayolu işletmelerinin maliyet ve verimliliklerini etkileyen faktörler tespit edilmeye çalışılmıştır. Uçak büyüklüğü ve farklı uçak tipleri gibi havayolu işletmesinin büyüklüğünü gösteren unsurların hem maliyet etkinliği hem tahsis etkinliği hem de teknik etkinlik açısından önemli olduğu tespit edilmiştir. Bununla birlikte ilgili havayolu işletmelerinin sahip olduğu yeni nesil uçakların yakıt tasarrufu dışında teknik etkinlik üzerinde bir etkisi olmadığı ancak maliyet ve tahsis etkinliği açısından önemli bir etkiye sahip olduğu belirtilmiştir (Merkert ve Hensher, 2011).

Hava taşımacılığı sektöründe veri zarflama analizi ile ilgili yapılan bazı çalışmaların havayolu işletmelerinin uygulamış olduğu iş modeline göre ayırarak etkinliklerini ölçtüğü görülmüştür (Yu vd., 2016). Lee ve Worthington, geleneksel havayolu işletmeleri ile düşük maliyetli havayolu işletmelerinin etkinliklerini karşılaştırmak amacı ile yapmış oldukları çalışmada 13 düşük maliyetli ve 29 geleneksel havayolu işletmesinin 2001-2005 yılları arasındaki etkinliğini ilk aşamada VZA aracılığı ile ölçmüştür. İkinci aşamada ise verimliliği etkileyen faktörlerin tespit edilmesi amacı ile truncated regresyon analizi kullanılmıştır. Analiz sonucunda Geleneksel havayolu işletmelerinin düşük maliyetli havayolu işletmeleri ile rekabet edebilmesi için operasyonel faaliyetlerini tekrar gözden geçirmeleri gerektiği belirtilmiştir. Bununla birlikte düşük maliyetli havayolu işletmelerinin etkinlik skorlarının geleneksel havayolu işletmelerine göre daha yüksek olduğu görülmüştür (Lee ve Worthington, 2014).

Bu çalışmada 2008 yılında ortaya çıkan ve daha sonraki yıllarda etkisini derinden hissettiren küresel finansal krizin havayolu işletmelerine olan etkisinin tespit edilmesi amacı ile dünyanın birçok farklı bölgesinde faaliyet gösteren 45 havayolu işletmesinin 2010-2016 yılları arasındaki 
etkinliği ilk aşamada VZA ile ölçülmüştür. İkinci aşamada ise finansal ve operasyonel verimliliği etkileyen faktörlerin tespit edilmesi amacı ile Tobit regresyon modeli uygulanmıştır. İlgili alan yazında 2008' deki küresel finansal krizin havayolu işletmelerinin finansal ve operasyonel performansına olan etkilerinin ölçüldüğü çalışma sayısının az olduğu tespit edilmiştir. Bununla birlikte ilgili dönem itibari ile VZA ve Tobit Regresyon analizinin birlikte kullanıldığı çalışma sayısının da az olduğu görülmüştür. Bu açıdan çalışmanın literatüre önemli katkı sağlaması beklenmektedir.

\section{Veri ve Yöntem}

\subsection{Veri Zarflama Analizi}

Veri zarflama analizi farklı ölçeklere sahip birçok girdi ve çıktının karşılaştııılmasının zor olduğu durumlarda kullanılan ve ilgili karar verme birimlerinin göreli etkinlik ölçümlerini yapan doğrusal programlama tabanlı bir ölçüm tekniğidir. Bununla birlikte VZA benzer girdilerin kullanılarak benzer çıktıların üretildiği birden fazla karar verme biriminin etkinliğinin ölçüldüğü durumlarda kullanılan parametrik olmayan bir ölçüm yöntemidir (Ramanathan, 2003: 26; Tütek vd., 2012: 223).

Veri zarflama analizinde analize dâhil edilecek karar verme birimlerinin benzer özellik taşıması, aynı amaç ve hedeflere sahip olması oldukça önemlidir. Ayrıca ilgili karar verme birimlerinin büyüklük ve yoğunluk dışındaki özelliklerinin aynı olması gereklidir (Karsak ve İşcan, 2000: 3).

Veri zarflama analizinde ilgili karar verme birimlerinin göreli etkinlik ölçümü yapılmakla birlikte kesin etkinlik değerlerine ulaşılamamaktadır. Bir başka ifade ile VZA etkin olan birimlerin etkin olmayan birimlere nazaran ne kadar etkin olduklarını ortaya koymaktadır (Yalçıner vd., 2005: 179).

Veri zarflama analizi tekniğinde minimum girdi bileşeni kullanarak maksimum çıktı bileşeni üreten en iyi karar verme birimleri tespit edilmekte ve tespit edilen bu karar verme birimleri etkinlik sınırını oluşturmaktadır. Belirlenen bu etkinlik sınırı referans noktası olarak kabul edilmektedir. Etkin olmayan karar verme birimlerinin etkinlik sınırına olan uzaklıkları radyal olarak ölçülüp oransal olarak ifade edilmektedir (Cook vd., 1996: 2).

Birçok girdi ve çıktıya sahip olan karar verme birimlerinin verimlilik ve etkinliklerinin ölçülmesine imkân tanıyan veri zarflama analizinin kullanılabilmesi için öncelikli olarak karar verme birimlerinin benzer organizasyona ve özelliğe sahip olması gerekmektedir. Kullanılan VZA modelinin ayrıştırma yeteneğinin iyi olabilmesi için kullanılan girdi ve çıktı değişken sayısının fazla olması istenmektedir. Bu açıdan girdi ve çıktı sayısının arttırılması etkinliğin daha ayrıntılı bir şekilde tespit edilmesine olanak sağlamaktadır. Ancak seçilen girdi ve çıktı kümesinin ilgili karar verme birimlerinin etkinlik durumunu en iyi şekilde yansıtması beklenmektedir. Analize dâhil edilecek çıktı sayısı " $s$ " ise girdi sayısı da " $m$ " ise karar verme birimi sayısının en az $m+s+1$ olması analizin güvenilirliği açısından oldukça önemli bir kısıttır. Başka bir görüşe göre ise karar verme birimi sayısı girdi ve çıktı toplamının en az 2 katına eşit olmalıdır (Atan, 2003: 75). VZA'da "ölçeğe göre sabit getiri" varsayımına dayanan CCR ile "ölçeğe göre değişken getiri" varsayıma dayanan BCC modelleri yaygın bir şekilde kullanılmaktadır (Ertuğrul ve Işık, 2008: 206). 


\subsubsection{CCR modeli}

Illk defa 1978 yılında kullanılmaya başlanan CCR modeli ölçeğe göre sabit getiri varsayımını temel almaktadır. CCR modelinde karar verme birimlerinin toplam etkinliği ölçülebilmektedir. Ayrıca bir karar verme biriminin CCR modeline göre etkin olabilmesi için hem teknik açıdan hem de ölçek açısından etkin olması gerekmektedir (Lorcu, 2008: 71). CCR modelinin matematiksel gösterimi şu şekildedir (Yolalan, 1993: 46):

$$
\begin{gathered}
Q_{k}=\max \left(\theta+\varepsilon \sum_{i=1}^{m} S_{i}^{-}+\varepsilon \sum_{r=1}^{s} S_{r}^{+}\right) \\
\text {KIsıtlar, } \\
\sum_{J=1}^{n} X_{i j} \beta_{j}+S_{i}^{-}-X_{i k}=0 \quad i=1, \ldots \ldots m \\
\sum_{J=1}^{n} Y_{r j} \beta_{j}-S_{i}^{-}-\beta Y_{k}=0 \quad r=1, \ldots . p \quad j=1, \ldots n \quad i=1, \ldots . m \\
\beta_{j} \geq 0 \quad S_{i}^{-} \geq 0 \quad S_{r}^{+} \geq 0
\end{gathered}
$$

\subsubsection{BCC modeli}

1984 yılında Banker, Charnes ve Rhodes'un CCR modeline, ölçeğe göre değişken getiri varsayımını temel alan konvekslik kısıtını eklemesi ile BCC modeli oluşmuştur. BCC modelinin CCR modelinden ayrılan özelliği sadece teknik etkinliği ölçmesidir. Çıktı odaklı BCC modelinin matematiksel ifadesi şu şekildedir (Cooper vd., 2007: 90):

$$
\begin{aligned}
& E_{o}=\operatorname{Max}\left(\theta+\varepsilon \sum_{i=i}^{m} S_{i}^{-}+\varepsilon \sum_{r=1}^{p} S_{r}^{+}\right) \quad(4) \\
& \text { Kısıtlar, } \\
& \sum_{j=1}^{n} X_{i j} \beta_{j}+S_{i}^{-}-X_{i k}=0 \quad i=1,2, \ldots m \quad(5) \\
& \sum_{j=1}^{n} y_{r j} \beta_{j}-\theta Y_{r k}-S_{r}^{+}=0 \quad r=1,2, \ldots p \quad(6) \\
& \sum_{j=1}^{n} \beta_{j}=1 \quad \beta_{j} \geq 0 \quad S_{i}^{-} \geq 0 \quad S_{i}^{+} \geq 0 \quad j=1,2, \ldots n \quad i=1,2 \ldots . m \quad r=1,2, \ldots . p
\end{aligned}
$$

\subsection{Tobit Modeli}

Uygulanan bir regresyon modelinde, bağımlı değişkene ait tüm gözlem değeri elde edilemiyor ya da bağımlı değişkene ilişkin tüm değerleri gözlenebiliyor ancak belli bir aralıkta tanımlanıyor ise (0-1 aralığı gibi) farklı bir tahmin yöntemi kullanılarak model tahmin edilmelidir (Şengül vd., 2013: 87-88). Veri zarflama analizi sonucunda elde edilen etkinlik skorları incelendiğinde, bu etkinlik değerlerinin [0-1] aralığında sınırlandığı görülmektedir. Dolaysıyla sınırlandııılmış olan bağımlı değişken değerleri ve etkinlik değerlerinin dağılım özelliklerini dikkate alan çoklu istatistiki bir model tarafından analiz edilmesi gerekmektedir (Kaplan ve Çelik, 2007: 103-104). Tobin tarafından 1958 yılında geliştirilen Tobit modeli, bağımlı değişkenini değişim aralığının 
herhangi bir nedenden dolayı sınırlandığı durumlarda kullanılabilir (Üçdoruk vd., 2001: 14). Bağımlı değişkene ait bilgilerin yalnızca bazı gözlemler için söz konusu olduğu örneklem türü, sansürlü örneklem olarak bilinmektedir. Bu nedenle Tobit Modeli, sansürlü model ya da kesikli regresyon modeli olarak da adlandırılmaktadır (Gujarati, 2004: 616 ). Tobit modelinde ya da sansürlü normal regresyon modelinde, gizli (latent) değişken doğrusal, bozucu terimleri sıfır ortalama ve eşit varyansa sahiptir. Tobit modeline ilişkin denklem aşağıdaki gibi yazılabilir (Şengül vd., 2013: 88);

$$
\begin{gathered}
y_{i}^{*}=x_{i}^{\prime} \beta+\varepsilon_{i} \quad(i=1 \ldots . n) \\
y_{i}=\left\{\begin{array}{c}
y_{i}^{*}>0 \text { ise } y_{i}=y_{i}^{*} \\
y_{i}^{*} \leq 0 \text { ise } y_{i}=0
\end{array}\right.
\end{gathered}
$$

$x_{i}^{\prime}=$ Tüm durumlar için gözlenen bağımsız değişken,

$y_{i}=0$ 'a eşit ya da 0'dan daha büyük veya daha küçük değerlerle sınırlandırılmış gizli (latent) bağımlı değişken,

$\beta=$ Tahmin edilecek katsayılar,

$\varepsilon_{i}=$ Hata terimini (bozucu terimi) göstermektedir.

Burada $y_{i}$ aynı zamanda veri zarflama analizi sonucunda elde edilen etkinlik skorlarını göstermektedir. Veri zarflama analizinde elde edilen etkinlik değerleri [0-1] aralığında sınırlandırıdığından, bu çalışmada sansürlenmiş Tobit modeli kullanılmıştır. Dolayısıyla, üstten (ya da sağdan) 1 noktasında sansürlenmiş Tobit modeli aşağıdaki gibi gösterilebilir.

$$
\begin{array}{cc}
y_{i}^{*}= & x_{i}^{\prime} \beta+\varepsilon_{i} \\
y=\left\{\begin{array}{lll}
y^{*} & \text { ise } & y^{*}<1 \\
1 & \text { ise } & y^{*} \geq 1
\end{array}\right.
\end{array}
$$

\section{Ampirik Bulgular}

Bu çalışmada dünyanın çeşitli bölgelerinde faaliyet gösteren 45 havayolu şirketinin etkinlik analizi veri zarflama analizi yöntemi kullanılarak incelenmiştir. Çalışmanın devamında veri zarflama analizinden elde edilen etkinlik skorları, bağımlı değişken olarak kullanılarak etkinliği belirleyen faktörler Tobit modeli kullanılarak analiz edilmiştir. Çalışma kapsamında havayolu şirketlerine ait veriler 2010-2016 dönemi için incelenmiştir. Havayolu şirketlerine ait verilerin elde edilmesinde farklı veri kaynaklarından yararlanılmıştır. Bu veri kaynaklar; Thomson Reuters Datastream veri tabanı, aylık olarak yayınlanan Flight Airline Business dergisi ve havayolu şirketlerinin faaliyet raporları şeklinde sıralanabilir.

Havayolu şirketlerinin performans analizinde kullanılacak girdi (input) ve çıktının (output) belirlenmesi ve seçimi son derece önemlidir. Bu çalışmada karar verme birimlerinin kullandığı girdileri ve elde edilen çıktıları belirlemek amacıyla literatürde yer alan çalışmalardan yararlanılmıştır. Buna ek olarak havayolu taşımacılığında sıklıkla kullanılan ve havayolu şirketlerinin en temel performans göstergeleri arasında yer alan değişkenler de kullanılmıştır. Çalışmada kullanılan girdi ve çıktılar aşağıdaki tabloda gösterilmektedir. 
Tablo 1: VZA Analizinde Kullanılan Girdi ve Çıktı Değişkenleri

\begin{tabular}{cll}
\hline Kısaltma & Girdi (Bağımsız Değişkenler) & Açıklama \\
\hline EMP & Çalışan Sayısı & Havayolunda çalışan toplam kişi sayısı \\
ASK & Arz edilen koltuk kilometre & Satışa sunulmuş koltuk sayısı x uçuş mesafesi (km) \\
FLT & Filo & Havayolunda bulunan toplam uçak sayısı \\
EXP & Faaliyet giderleri & ilgili dönemde faaliyetlere ilişkin gider toplamı \\
\hline Kısaltma & Çıktı (Bağımsız Değişkenler) & Açıklama \\
\hline RPK & Ücretli yolcu kilometre & Ücret karşı̆ı̆ı taşınan yolcu sayısı x uçuş mesafesi (km) \\
PAX & Yolcu Sayısı & Havayolunun taşıdığı toplam yolcu sayısı \\
LOAD & Doluluk Oranı & (RPK/ASK)x100 \\
REV & Faaliyet geliri & ilgili dönemde faaliyetlerden elde edilen gelir toplamı \\
\hline Kısaltma & Bağımlı Değişkenler & Açıklama \\
\hline PTE & Teknik Etkinlik & Ölçeğe göre değişken getiri varsayımında etkinlik ölçümü \\
SE & Ölçek Etkinliği & Toplam etkinlik düzeyinin teknik etkinlik düzeyine oranı \\
TE & Toplam Etkinlik & Ölçeğe göre sabit getiri varsayımında etkinlik ölçümü \\
\hline
\end{tabular}

\subsection{Veri Zarflama Analizi Bulguları}

Havayolu işletmelerine ilişkin girdi ve çıktılar belirlendikten sonra 2010-2016 dönemi için havayolu şirketlerinin etkinlik analizi VZA yöntemi kullanılarak analiz edilmiştir. Havayolu işletmelerinde veri zarflama analiziyle etkinlik ölçümü ile ilgili yapılan çalışmalara bakıldığında iki farklı görüşün olduğu görülmüştür. Birinci görüşe göre, ilgili işletmelerin girdi değişkenleri üzerinde çıktı değişkenlerine nazaran daha fazla etkiye sahip olduğundan dolayı, girdi odaklı VZA modelinin kullanılması gerektiği savunulmaktadır (Saranga ve Nagpal, 2016; Yu vd., 2016). Bir diğer görüşe göre ise ilgili işletmelerin çıktı değişkenleri üzerinde daha fazla etkiye sahip olduğundan dolayı, çıktı odaklı modelin kullanılması gerektiği savunulmaktadır (Assaf ve josiassen, 2009; Barros ve Peypoch, 2009; Bhadra, 2009). Bu açıdan çalışmada, kullanılan girdi ve çıktı değişkenlerinden dolayı çıkıtı odaklı VZA modelinin kullanılmasına karar verilmiştir. Analize dahil edilen havayolu işletmelerinin etkinlik ölçümü DEAP 2.1 ve EMS 1.3 yazılım programları kullanılarak gerçekleştirilmiştir.

Analize dâhil edilen 45 havayolu şirketinin yıllara göre etkinlik değerleri aşağıdaki tabloda gösterildiği gibidir. 
Eskişehir Osmangazi Üniversitesi iißBF Dergisi

Tablo 2: 2010-2016 Dönemi Havayollarının Etkinlik Skorları (Çıktı odaklı CCR ve BCC modeli)

\begin{tabular}{|c|c|c|c|c|c|c|c|c|c|c|c|c|c|c|}
\hline \multirow{2}{*}{ KOD } & \multicolumn{2}{|c|}{2010} & \multicolumn{2}{|c|}{2011} & \multicolumn{2}{|c|}{2012} & \multicolumn{2}{|c|}{2013} & \multicolumn{2}{|c|}{2014} & \multicolumn{2}{|c|}{2015} & \multicolumn{2}{|c|}{2016} \\
\hline & CCR & BCC & CCR & BCC & CCR & BCC & CCR & BCC & CCR & BCC & CCR & BCC & CCR & BCC \\
\hline $\mathrm{El}$ & 0.988 & 1 & 1 & 1 & 1 & 1 & 1 & 1 & 1 & 1 & 1 & 1 & 1 & 1 \\
\hline SU & 0.911 & 0.911 & 0.913 & 0.92 & 0.969 & 0.969 & 0.929 & 0.93 & 0.894 & 0.894 & 0.907 & 0.91 & 0.911 & 0.929 \\
\hline AM & 0.964 & 0.967 & 0.976 & 0.988 & 0.952 & 0.974 & 0.93 & 0.933 & 1 & 1 & 1 & 1 & 1 & 1 \\
\hline$A B$ & 1 & 1 & 1 & 1 & 1 & 1 & 1 & 1 & 1 & 1 & 1 & 1 & 1 & 1 \\
\hline$A C$ & 0.952 & 0.96 & 0.972 & 0.977 & 0.98 & 0.989 & 0.989 & 0.995 & 1 & 1 & 1 & 1 & 1 & 1 \\
\hline$C A$ & \begin{tabular}{|l|}
0.966 \\
\end{tabular} & 1 & 1 & 1 & 1 & 1 & 1 & 1 & 1 & 1 & 1 & 1 & 1 & 1 \\
\hline $\mathrm{AF} / \mathrm{KL}$ & \begin{tabular}{|l|}
0.997 \\
\end{tabular} & 1 & 1 & 1 & 1 & 1 & 1 & 1 & 1 & 1 & 1 & 1 & 1 & 1 \\
\hline NZ & 1 & 1 & 1 & 1 & 1 & 1 & 1 & 1 & 1 & 1 & 1 & 1 & 1 & 1 \\
\hline$A K$ & 1 & 1 & 1 & 1 & 1 & 1 & 1 & 1 & 1 & 1 & 1 & 1 & 1 & 1 \\
\hline AS & 0.959 & 0.963 & 0.985 & 0.996 & 0.941 & 1 & 1 & 1 & 0.986 & 1 & 1 & 1 & 1 & 1 \\
\hline $\mathrm{NH}$ & 1 & 1 & 1 & 1 & 1 & 1 & 1 & 1 & 1 & 1 & 1 & 1 & 1 & 1 \\
\hline $\mathrm{OZ}$ & 1 & 1 & 1 & 1 & 0.998 & 0.998 & 0.951 & 0.953 & 0.989 & 0.992 & 1 & 1 & 1 & 1 \\
\hline AV & 1 & 1 & 1 & 1 & 1 & 1 & 1 & 1 & 1 & 1 & 0.986 & 0.991 & 0.959 & 0.96 \\
\hline$C X$ & 1 & 1 & 1 & 1 & 0.991 & 1 & 1 & 1 & 1 & 1 & 1 & 1 & 1 & 1 \\
\hline $\mathrm{Cl}$ & 0.961 & 0.961 & 0.936 & 0.936 & 0.893 & 0.929 & 0.907 & 0.908 & 0.911 & 0.92 & 0.915 & 0.927 & 0.907 & 0.914 \\
\hline $\mathrm{MU}$ & \begin{tabular}{|l|}
0.935 \\
\end{tabular} & 0.957 & 0.963 & 1 & 0.936 & 1 & 0.996 & 1 & 0.972 & 1 & 0.916 & 0.928 & 0.948 & 0.956 \\
\hline $\mathrm{CZ}$ & 0.912 & 0.951 & 0.944 & 0.968 & 0.856 & 0.952 & 0.9 & 0.936 & 0.902 & 0.945 & 0.922 & 0.93 & 0.919 & 0.931 \\
\hline $\mathrm{CM}$ & 1 & 1 & 0.951 & 0.955 & 0.909 & 0.926 & 1 & 1 & 0.956 & 0.962 & 0.902 & 0.91 & 0.934 & 0.936 \\
\hline $\mathrm{DL}$ & 0.963 & 1 & 0.981 & 1 & 0.976 & 1 & 0.976 & 1 & 0.958 & 1 & 1 & 1 & 1 & 1 \\
\hline U2 & 1 & 1 & 1 & 1 & 1 & 1 & 1 & 1 & 1 & 1 & 1 & 1 & 1 & 1 \\
\hline LY & 1 & 1 & 1 & 1 & 1 & 1 & 1 & 1 & 1 & 1 & 1 & 1 & 1 & 1 \\
\hline $\mathrm{BR}$ & 0.956 & 0.959 & 0.938 & 0.938 & 0.923 & 0.953 & 0.935 & 0.947 & 0.918 & 0.922 & 0.948 & .959 & 0.932 & 0.937 \\
\hline AY & 0.914 & 0.914 & 0.877 & 0.877 & 1 & 1 & 1 & 1 & 1 & 1 & 1 & 1 & 1 & 1 \\
\hline GA & 0.8 & 0.806 & 0.905 & 0.91 & 0.827 & 0.912 & 0.858 & 0.871 & 0.813 & 0.83 & 0.972 & 0.981 & 0.944 & 0.964 \\
\hline G3 & 1 & 1 & 1 & 1 & 1 & 1 & 0.927 & 0.946 & 1 & 1 & 1 & 1 & 0.974 & 0.998 \\
\hline $\mathrm{HU}$ & 1 & 1 & 1 & 1 & 1 & 1 & 1 & 1 & 1 & 1 & 0.972 & 0.985 & 1 & 1 \\
\hline $\mathrm{HA}$ & 1 & 1 & 1 & 1 & 1 & 1 & 1 & 1 & 1 & 1 & 1 & 1 & 1 & 1 \\
\hline QJ & \begin{tabular}{|l|} 
\\
\end{tabular} & 0.922 & 0.934 & 0.937 & 0.847 & 0.935 & 0.91 & 0.92 & 0.938 & 0.956 & 0.935 & 0.964 & 0.916 & 0.928 \\
\hline $\mathrm{B} 6$ & \begin{tabular}{|l|}
0.937 \\
\end{tabular} & 0.941 & 0.951 & 0.953 & 0.884 & 0.957 & 0.932 & 0.943 & 0.942 & 0.951 & 0.953 & 0.958 & 0.96 & 0.969 \\
\hline $\mathrm{KE}$ & 1 & 1 & 1 & 1 & 1 & 1 & 1 & 1 & 1 & 1 & 0.976 & 0.976 & 0.977 & 0.977 \\
\hline LA & 1 & 1 & 1 & 1 & 1 & 1 & 1 & 1 & 1 & 1 & 1 & 1 & 1 & 1 \\
\hline $\mathrm{LH}$ & 1 & 1 & 1 & 1 & 1 & 1 & 1 & 1 & 1 & 1 & 1 & 1 & 1 & 1 \\
\hline $\mathrm{D} 8$ & 1 & 1 & 1 & 1 & 1 & 1 & 1 & 1 & 1 & 1 & 1 & 1 & 1 & 1 \\
\hline QF & 1 & 1 & 1 & 1 & 1 & 1 & 1 & 1 & 1 & 1 & 1 & 1 & 1 & 1 \\
\hline $\mathrm{FR}$ & 1 & 1 & 1 & 1 & 1 & 1 & 1 & 1 & 1 & 1 & 1 & 1 & 1 & 1 \\
\hline SK & 1 & 1 & 1 & 1 & 1 & 1 & 1 & 1 & 1 & 1 & 1 & 1 & 0.973 & 0.982 \\
\hline SC & 1 & 1 & 1 & 1 & 1 & 1 & 1 & 1 & 1 & 1 & 0.966 & 0.978 & 0.911 & 0.922 \\
\hline SQ & 1 & 1 & 1 & 1 & 1 & 1 & 1 & 1 & 1 & 1 & 1 & 1 & 1 & 1 \\
\hline 00 & 1 & 1 & 1 & 1 & 1 & 1 & 1 & 1 & 1 & 1 & 1 & 1 & 1 & 1 \\
\hline WN & \begin{tabular}{|l|}
0.908 \\
\end{tabular} & 0.989 & 0.931 & 1 & 0.867 & 1 & 0.917 & 1 & 0.933 & 1 & 1 & 1 & 0.99 & 1 \\
\hline TG & 0.993 & 0.994 & 0.962 & 0.967 & 1 & 1 & 1 & 1 & 1 & 1 & 1 & 1 & 1 & 1 \\
\hline TK & \begin{tabular}{|l|}
0.871 \\
\end{tabular} & 0.874 & 0.883 & 0.892 & 0.925 & 0.93 & 0.948 & 0.952 & 0.921 & 0.946 & 0.88 & 0.907 & 0.853 & 0.862 \\
\hline UA & 1 & 1 & 1 & 1 & 0.944 & 1 & 0.96 & 1 & 0.966 & 1 & 0.97 & 1 & 0.981 & 1 \\
\hline VA & 0.933 & 0.933 & 0.931 & 0.94 & 0.907 & 0.925 & 0.934 & 0.934 & 0.896 & 0.909 & 0.924 & 0.926 & 0.947 & 0.949 \\
\hline WS & 0.939 & 0.939 & 0.928 & 0.943 & 0.947 & 0.984 & 0.96 & 0.971 & 0.951 & 0.963 & 0.927 & 0.948 & 0.921 & 0.94 \\
\hline
\end{tabular}

Not: Çalışmada yer tasarrufu sağlamak amacıyla havayolu şirketlerinin isimleri yerine IATA (International Air Transport Association) tarafından verilen ikili kısaltma kodları kullanılmıştır. 
Tablo 2'de Veri zarflama analizinin çıktı odaklı CCR ve BCC modeline göre 2010-2016 yılları arasında yapılan etkinlik ölçümünde SU (Aeroflot), CI (China Aırlınes), CZ (China Southern), BR (Eva Airways), GA (Garuda Indonesia), QJ (Jet Airways), B6 (Jet Blue Airways), TK (Türk Havayolları), VA (Virgin Australia) ve WS (Westjet Airlines) kodlu havayollarının ilgili dönem itibari ile etkin çıkmadıkları görülmüştür. AB (AirBerlin), NZ (Air Newzealand), AK (AirAsia), NH (All Nippon Airways), U2(EasyJet), LY (El Al Airlines), HA (Hawaiian Airlines), LA (Latam Airlines), LH (Lufthansa Airlines), D8 (Norwegian Air), QF (Qantas Airways), FR (Ryan Air), SQ (Singapore Airlines) ve OO (SkyWest) kodlu havayollarının etkin oldukları tespit edilmiştir. DL kodlu Delta Havayollarının 2010-2014 döneminde ise çıktı odaklı CCR modeline göre etkin değilken çıktı odaklı BCC modeline göre etkin çıktığı görülmüştür. Aynı şekilde EI kodlu Aer Lingus havayolu işletmesinin 2010 yılında çıktı odaklı CCR modeline göre etkin değilken çıktı odaklı BCC modeline göre etkin çıktığı tespit edilmiştir. CX kodlu (Cathay Pacific) Havayolunun sadece 2012 yılında etkin çıkmadığı görülmüştür. HU kodlu (Hainan Airlines) havayolunun sadece 2015 ve SK kodlu (SAS Airlines) havayolunun sadece 2016 yılında etkin çıkmadığı tespit edilmiştir. Diğer havayolu işletmelerinin ise verimlilik ve etkinlik durumlarının yıllara göre değişkenlik gösterdiği görülmüştür. Ayrıca düşük maliyetli havayolu işletmeleri içerisinde B6 (Jet Blue Airways), VA (Virgin Australia) ve WS (Westjet Airlines) kodlu havayollarının ilgili dönem itibari ile etkin çıkmadıkları tespit edilmiştir.

Veri zarflama analizinin süper etkinlik modeli, ilgili havayolu işletmelerini kendi içerisinde en yüksek etkinlik değerine sahip olandan en düşük etkinlik değerine sahip olana doğru sıralama imkânı sunmaktadır. Bu açıdan analize dâhil edilen havayolu işletmelerinin süper ekinlik modeline göre yapılan etkinlik ölçümü sonucunda oluşan etkinlik sıralaması Tablo 3'de verilmiştir.

Tablo 3: 2010-2016 Dönemi Havayollarının Süper Etkinlik Sıralaması

\begin{tabular}{|c|c|c|c|c|c|c|c|c|c|c|c|c|c|c|c|}
\hline Sira & 2010 & 2011 & 2012 & 2013 & 2014 & 2015 & 2016 & Sira & 2010 & 2011 & 2012 & 2013 & 2014 & 2015 & 2016 \\
\hline 1 & FR & D8 & D8 & AK & AK & LA & AK & 24 & $\mathrm{AF} / \mathrm{KL}$ & SU & $\mathrm{LH}$ & AS & TG & AS & $C X$ \\
\hline 2 & D8 & AV & AK & LA & FR & AK & $A B$ & 25 & TG & AM & $\mathrm{OZ}$ & $\mathrm{KE}$ & $C X$ & $\mathrm{DL}$ & LA \\
\hline 3 & SC & $\mathrm{AK}$ & LA & LY & $\mathrm{EI}$ & $\mathrm{FR}$ & $\mathrm{FR}$ & 26 & SQ & AS & $\mathrm{AF} / \mathrm{KL}$ & $\mathrm{AF} / \mathrm{KL}$ & SK & SK & $\mathrm{DL}$ \\
\hline 4 & AK & FR & FR & EI & AM & EI & EI & 27 & El & $\mathrm{Cl}$ & $A C$ & $C X$ & $A C$ & WN & WN \\
\hline 5 & 00 & SC & LY & $\mathrm{D} 8$ & LA & $L Y$ & 00 & 28 & AM & $\mathrm{CM}$ & $\mathrm{DL}$ & $A C$ & $\mathrm{NH}$ & $A C$ & UA \\
\hline 6 & $\mathrm{HA}$ & $\mathrm{NH}$ & G3 & U2 & U2 & 00 & LY & 29 & $C A$ & $\mathrm{BR}$ & $C X$ & $\mathrm{DL}$ & $\mathrm{OZ}$ & AV & KE \\
\hline 7 & UA & $\mathrm{HA}$ & $\mathrm{AV}$ & 00 & $L Y$ & U2 & $C A$ & 30 & $\mathrm{Cl}$ & $\mathrm{AY}$ & SU & $\mathrm{MU}$ & AS & $\mathrm{KE}$ & G3 \\
\hline 8 & $\mathrm{NH}$ & KE & $\mathrm{EI}$ & FR & 00 & $\mathrm{NZ}$ & U2 & 31 & AS & GA & $A M$ & WS & UA & $\mathrm{HU}$ & SK \\
\hline 9 & SK & SK & $\mathrm{NH}$ & QF & $A Y$ & $A B$ & $\mathrm{AF} / \mathrm{KL}$ & 32 & $\mathrm{BR}$ & G3 & WS & $\mathrm{OZ}$ & $\mathrm{MU}$ & GA & B6 \\
\hline 10 & AV & LY & SC & $S Q$ & D8 & $\mathrm{AF} / \mathrm{KL}$ & $\mathrm{NH}$ & 33 & WS & QJ & UA & UA & $\mathrm{CM}$ & UA & $\mathrm{AV}$ \\
\hline 11 & $A B$ & $\mathrm{HU}$ & $\mathrm{U} 2$ & SK & $A B$ & $\mathrm{D} 8$ & $\mathrm{HA}$ & 34 & B6 & $\mathrm{B} 6$ & AS & TK & WS & SC & $\mathrm{MU}$ \\
\hline 12 & LH & SQ & SQ & $A Y$ & $S Q$ & QF & TG & 35 & $\mathrm{MU}$ & LA & TK & $B R$ & $\mathrm{DL}$ & B6 & VA \\
\hline 13 & LA & $A B$ & $\mathrm{NZ}$ & $\mathrm{SC}$ & QF & $C A$ & $\mathrm{LH}$ & 36 & VA & 00 & $B R$ & VA & B6 & $B R$ & $\mathrm{GA}$ \\
\hline 14 & G3 & U2 & 00 & $A B$ & $\mathrm{HA}$ & $\mathrm{HA}$ & AS & 37 & $\mathrm{DL}$ & TG & $\mathrm{MU}$ & B6 & QJ & QJ & $\mathrm{CM}$ \\
\hline 15 & $C X$ & LH & KE & AV & $\mathrm{NZ}$ & TG & $\mathrm{NZ}$ & 38 & QJ & TK & $\mathrm{CM}$ & AM & WN & WS & $\mathrm{BR}$ \\
\hline 16 & U2 & $\mathrm{EI}$ & SK & $\mathrm{NZ}$ & LH & $\mathrm{OZ}$ & $S Q$ & 39 & $A C$ & VA & $\mathrm{VA}$ & SU & TK & VA & WS \\
\hline 17 & $\mathrm{OZ}$ & $\mathrm{OZ}$ & $A Y$ & TG & G3 & $\mathrm{SQ}$ & $A C$ & 40 & $A Y$ & WS & $\mathrm{Cl}$ & G3 & $\mathrm{BR}$ & $\mathrm{Cl}$ & QJ \\
\hline 18 & QF & UA & $\mathrm{HA}$ & $\mathrm{HA}$ & SC & $\mathrm{LH}$ & AY & 41 & SU & $A C$ & B6 & QJ & $\mathrm{Cl}$ & $\mathrm{MU}$ & SC \\
\hline 19 & $\mathrm{CM}$ & $C A$ & QF & $\mathrm{CM}$ & $\mathrm{KE}$ & $A Y$ & AM & 42 & $\mathrm{CZ}$ & $\mathrm{DL}$ & WN & $\mathrm{Cl}$ & VA & SU & SU \\
\hline 20 & LY & $\mathrm{AF} / \mathrm{KL}$ & $\mathrm{HU}$ & $\mathrm{HU}$ & AV & G3 & $\mathrm{HU}$ & 43 & TK & $\mathrm{CZ}$ & QJ & WN & SU & CM & $\mathrm{Cl}$ \\
\hline 21 & KE & $\mathrm{NZ}$ & TG & $\mathrm{NH}$ & $\mathrm{CA}$ & $C X$ & $\mathrm{D} 8$ & 44 & WN & $\mathrm{MU}$ & $\mathrm{GA}$ & $\mathrm{CZ}$ & $\mathrm{CZ}$ & $\mathrm{CZ}$ & $\mathrm{CZ}$ \\
\hline 22 & $\mathrm{NZ}$ & $c X$ & $\mathrm{CA}$ & $\mathrm{LH}$ & $\mathrm{HU}$ & $\mathrm{NH}$ & $\mathrm{OZ}$ & 45 & $\mathrm{GA}$ & WN & $\mathrm{CZ}$ & GA & $\mathrm{GA}$ & TK & TK \\
\hline 23 & $\mathrm{HU}$ & QF & $A B$ & $\mathrm{CA}$ & $\mathrm{AF} / \mathrm{KL}$ & AM & QF & & & & & & & & \\
\hline
\end{tabular}


Tablo 3'de VZA'nın süper etkinlik modeline göre yapılan etkinlik ölçüm sıralamasına göre 2010 yılında RyanAir(FR)'in, 2011 ve 2012 yılında Norwegian Air(D8)'in, 2013, 2014 ve 2016 yılında AirAsia(AK)'nın, 2015 yılında ise Latam Airlines(LA)'ın süper etkinlik sıralamasında ilk sırada yer aldığı görülmüştür.

Veri zarflama analizi aracılığı ile etkinlik sınırının altında kalan karar verme birimlerinin etkinlik sınırına ulaşabilmeleri için referans almaları gereken karar verme birimleri tespit edilerek referans kümesi oluşturulmaktadır. Etkin olmayan havayolu işletmelerinin etkin duruma geçebilmesi için referans alması gereken havayolu işletmeleri ve bu havayolu işletmelerinin 20102016 yılına ait referans değerleri EK 2'de verilmiştir.

Veri zarflama analizinde etkinlik sınırının altında kalan havayolu işletmelerinin etkinlik sınırına ulaşabilmeleri için mevcut girdi ve çıktı değişkenlerini azaltmaları veya arttırmaları gerekmektedir. Bu açıdan çıktı odaklı CCR ve BCC modeline göre etkinlik sınırının altında kalan havayolu işletmelerinin etkinlik sınırına ulaşabilmeleri için mevcut çıktı değişkenlerini ne kadar değiştirmeleri gerektiği EK-3 ve EK-4'de verilmiştir. Yer tasarrufu sağlanması amacı ile sadece 2010 yılına ait mevcut ve hedef girdi değişkenleri verilmiştir.

\subsection{Tobit Model Analiz Bulguları}

Havayolu şirketlerinin etkinlik değerleri veri zarflama analizi kullanılarak elde edildikten sonra, etkinlik skorlarını belirleyen faktörlerin ortaya çıkarılması amacıyla Tobit analizi uygulanmıştır. Bu sayede havayollarının etkinliklerini etkileyen faktörler ve etkinlik farklılıklarının nedenlerinin tespit edilmesi amacıyla kurulan regresyon modelleri aşağıdaki gibidir.

Tablo 4: Tobit Regresyon Modelleri

$$
\begin{gathered}
\text { Model } 1 \\
P T E_{i t}=\beta_{0}+\beta_{1} E M P_{i t}+\beta_{2} A S K_{i t}+\beta_{3} F L T_{i t}+\beta_{4} E X P_{i t}+\beta_{5} R P K_{i t}+\beta_{6} P A X_{i t}+\beta_{7} L O A D_{i t}+\beta_{8} R E V_{i t} \\
+\varepsilon_{i t}
\end{gathered}
$$

Model $2 S E_{i t}=\beta_{0}+\beta_{1} E M P_{i t}+\beta_{2} A S K_{i t}+\beta_{3} F L T_{i t}+\beta_{4} E X P_{i t}+\beta_{5} R P K_{i t}+\beta_{6} P A X_{i t}+\beta_{7} L O A D_{i t}+\beta_{8} R E V_{i t}+\varepsilon_{i t}$

Model $3 \quad T E_{i t}=\beta_{0}+\beta_{1} E M P_{i t}+\beta_{2} A S K_{i t}+\beta_{3} F L T_{i t}+\beta_{4} E X P_{i t}+\beta_{5} R P K_{i t}+\beta_{6} P A X_{i t}+\beta_{7} L O A D_{i t}+\beta_{8} R E V_{i t}+\varepsilon_{i t}$

Tablo 4'de oluşturulan Tobit modellerine yer verilmektedir. Buna göre model 1'de teknik etkinliği belirleyen faktörlere göre, model 2' de ölçek etkinliğinin belirleyicileri ve model 3'te ise toplam etkinliği belirleyen faktörler incelenmektedir. 
Tablo 5: Tobit Regresyon Model Sonuçları (Etkinsizliğin Kaynakları)

\begin{tabular}{ccccl}
\hline Bağımlı Değişken: PTE (Teknik Etkinsizlik) & Katsayı & Std. Hata & z & p-değeri \\
\hline Değişkenler & 0.0827 & 0.156287 & 0.53 & 0.597 \\
Sabit & $-7.54 \mathrm{E}-07$ & $8.12 \mathrm{E}-07$ & -0.93 & 0.353 \\
EMP & $3.73 \mathrm{E}-09$ & $2.33 \mathrm{E}-09$ & 1.6 & 0.11 \\
ASK & -0.000652 & 0.000125 & -5.23 & $0.000^{*}$ \\
FLT & $-1.45 \mathrm{E}-08$ & $5.21 \mathrm{E}-09$ & -2.79 & $0.005^{*}$ \\
EXP & $-5.92 \mathrm{E}-09$ & $2.93 \mathrm{E}-09$ & -2.02 & $0.044^{* *}$ \\
RPK & $2.76 \mathrm{E}-09$ & $6.32 \mathrm{E}-10$ & 4.37 & $0.000^{*}$ \\
PAX & 0.011554 & 0.001959 & 5.9 & $0.000^{*}$ \\
LOAD & $3.22 \mathrm{E}-08$ & $6.02 \mathrm{E}-09$ & 5.35 & $0.000^{*}$ \\
REV & & & Log likelihood $=161.305$ \\
\hline
\end{tabular}

Not: ${ }^{*}{ }^{* *}$ ve ${ }^{* * *}$ değerleri sırasıyla $\% 1, \% 5$ ve \%10 anlam seviyesinde test istatistiğinin anlamlı olduğunu göstermektedir.

Tablo 5'de havayolu şirketlerinin teknik etkinliklerini belirleyen faktörlere ilişkin Tobit regresyon analiz sonuçlarına yer verilmektedir. Buna göre havayolu şirketlerinin toplam uçak sayısında (filo), faaliyetlere ilişkin harcamalarda ve ücretli yolcu kilometre tutarında meydana gelen negatif yönlü değişim teknik etkinlik düzeyini azaltmaktadır. Buna karşın, taşınan toplam yolcu sayısı, doluluk oranı ve toplam gelirlerde meydana gelen artış, teknik etkinlik düzeyi üzerinde pozitif yönlü bir etkiye sahiptir.

Tablo 6: Tobit Regresyon Model Sonuçları (Etkinsizliğin Kaynakları)

\begin{tabular}{ccccl}
\hline Bağımlı Değişken: SE (Ölçek Etkinsizliği) & \multicolumn{1}{c}{} \\
\hline Değişkenler & Katsayı & Std. Hata & z & p-değeri \\
\hline Sabit & 0.250999 & 0.150339 & 1.67 & $0.095^{* * *}$ \\
EMP & $-1.14 \mathrm{E}-06$ & $6.44 \mathrm{E}-07$ & -1.77 & $0.077^{* *}$ \\
ASK & $1.98 \mathrm{E}-09$ & $1.77 \mathrm{E}-09$ & 1.12 & 0.263 \\
FLT & -0.000358 & 0.000084 & -4.29 & $0.000^{*}$ \\
EXP & $-1.39 \mathrm{E}-08$ & $3.39 \mathrm{E}-09$ & -4.1 & $0.000^{*}$ \\
RPK & $-3.43 \mathrm{E}-09$ & $2.20 \mathrm{E}-09$ & -1.56 & 0.119 \\
PAX & $1.33 \mathrm{E}-09$ & $4.98 \mathrm{E}-10$ & 2.67 & $0.008^{*}$ \\
LOAD & 0.009615 & 0.001881 & 5.11 & $0.000^{*}$ \\
REV & $2.46 \mathrm{E}-08$ & $4.13 \mathrm{E}-09$ & 5.96 & $0.000^{*}$ \\
\hline
\end{tabular}

Not: ${ }^{*}{ }^{* *}$ ve ${ }^{* * *}$ değerleri sırasıyla $\% 1, \% 5$ ve \%10 anlam seviyesinde test istatistiğinin anlamlı olduğunu göstermektedir.

Tablo 6'da havayolu şirketlerinin ölçek etkinliklerini belirleyen faktörlere ilişkin Tobit regresyon analiz sonuçlarına yer verilmiştir. Bu modelde bağımlı değişken olarak ölçek etkinlik (SE) düzeyi kullanılmıştır. Dolayısıyla bu modelde havayolu şirketlerinin ölçek etkinsizliğini belirleyen faktörler incelenmektedir. Ampirik analiz sonuçları, havayolu şirketlerinin yolcu sayısı, doluluk oranı ve toplam gelirler düzeyinde meydana gelen artışın, ölçek etkinlik düzeyi üzerinde pozitif yönlü bir etkiye sahip olduğu görülmektedir. Buna karşın çalışan sayısı, toplam uçak sayısı (filo) ve faaliyetlere ilişkin harcamalarında meydana gelen negatif yönlü değişimin ölçek etkinlik düzeyini azalttığına işaret etmektedir. 
Eskişehir Osmangazi Üniversitesi iißBF Dergisi

Tablo 7: Tobit Regresyon Model Sonuçları (Etkinsizliğin Kaynakları)

\begin{tabular}{ccccl}
\hline Bağımlı Değişken: TE (Toplam Etkinsizlik) & Katsayı & Std. Hata & z & p-değeri \\
\hline Değişkenler & 0.947213 & 0.095592 & 9.91 & $0.000^{*}$ \\
Sabit & $-4.68 \mathrm{E}-07$ & $3.38 \mathrm{E}-07$ & -1.39 & 0.166 \\
EMP & $-8.60 \mathrm{E}-10$ & $1.11 \mathrm{E}-09$ & -0.77 & 0.439 \\
ASK & -0.000152 & 0.000048 & -3.21 & $0.001^{*}$ \\
FLT & $-7.25 \mathrm{E}-09$ & $2.16 \mathrm{E}-09$ & -3.36 & $0.001^{*}$ \\
EXP & $6.59 \mathrm{E}-10$ & $1.38 \mathrm{E}-09$ & 0.48 & 0.632 \\
RPK & $3.31 \mathrm{E}-10$ & $2.74 \mathrm{E}-10$ & 1.2 & 0.228 \\
PAX & 0.001031 & 0.001191 & 0.87 & 0.387 \\
LOAD & $1.14 \mathrm{E}-08$ & $2.54 \mathrm{E}-09$ & 4.48 & $0.000^{*}$ \\
REV & & & Log likelihood $=192.635$ \\
\hline
\end{tabular}

Not: ${ }^{*}{ }^{* *}$ ve ${ }^{* * *}$ değerleri sırasıyla $\% 1, \% 5$ ve \%10 anlam seviyesinde test istatistiğinin anlamlı olduğunu göstermektedir.

Tablo 7'de havayolu şirketlerinin toplam etkinliklerini belirleyen faktörlere ilişkin Tobit regresyon analiz sonuçlarına yer verilmiştir. Bu modelde bağımlı değişken olarak toplam etkinlik (TE) düzeyi kullanılmıştır. Dolayısıyla havayolu şirketlerinin teknik etkinsizliğini belirleyen faktörler incelenmektedir. Ampirik analiz bulguları, havayolu şirketlerinin toplam uçak sayısında (filo) ve faaliyetlere ilişkin harcamalarında meydana gelen negatif yönlü değişimin toplam etkinlik düzeyini azalttığına işaret etmektedir. Ancak havayolu şirketlerinin toplam gelirler düzeyinde meydana gelen artışın, toplam etkinlik düzeyi üzerinde pozitif yönlü bir etkiye sahip olduğu görülmektedir.

\section{Sonuç}

Bu çalışmada dünyanın birçok farklı bölgesinde faaliyet gösteren toplam 45 havayolu işletmesinin 2010-2016 yılları arasındaki verimlilik ve etkinlik ölçümü ilk aşamada veri zarflama analizi ile gerçekleştirilmiştir. Bir sonraki aşamada ise verimliliği olumlu veya olumsuz etkileyen faktörlerin tespit edilmesi amacı ile Tobit regresyon modeli uygulanmıştır.

Araştırma kapsamında veri zarflama analizinin ölçeğe göre sabit getiri varsayımını temel alan çıktı odaklı CCR modeli ile ölçeğe göre değişken getiri varsayımını temel alan BCC modeli kullanılmıştır. Veri zarflama analizinin güvenilir sonuçlar vermesi için seçilen çıktı ve girdi değişkenlerinin kendi içerisinde anlamlı olması oldukça önemlidir. Bu açıdan bu çalışmada havayolu işletmelerinin verimlilik ve etkinliklerini doğrudan etkileyen girdi ve çıktı değişkenleri kullanılmıştır.

Analiz sonuçlarına göre 2010-2016 döneminde ilgili havayolu işletmelerinin sadece 14 tanesinin ele alınan tüm dönem boyunca etkin çıkmıştır. 10 tanesinin ise etkin çıkmadığı görülmüştür. Geri kalan 21 havayolu işletmesinin ise etkinlik durumlarının dalgalı bir seyir izlediği tespit edilmiştir. Veri zarflama analizinin süper etkinlik modeline göre yapılan etkinlik sıralamasına göre Air Asia (AK) havayolu işletmesinin 2010-2016 döneminin tümünde ilk beş içerisinde yer aldığı tespit edilmiştir. Aynı şekilde Ryan Air (FR), Norwegian Air (D8) ve Latam havayollarının ele alınan dönemin büyük bir kısmında ilk beşte yer aldığı görülmüştür.

Çalışmada havayolu şirketlerinin etkinlik düzeylerini belirleyen faktörlerin ortaya çıkarılması amacıyla Tobit regresyon analizi uygulanmıştır. Bu kapsamda teknik etkinlik (PTE), ölçek etkin- 
liği (SE) ve toplam etkinlik (TE) verileri bağımlı değişken olarak kullanılarak üç farklı model oluşturulmuştur. Çalışmanın bulguları her üç etkinlik düzeyini de etkileyen değişkenlerin benzerlik gösterdiğini ortaya koymaktadır. Bu durum çalışmada kurulan modellerin ve belirlenen açıklayıcı değişkenlerin tutarlı olduğuna işaret etmektedir. Çalışmanın ampirik sonuçları aynı zamanda, her üç model içinde toplam uçak sayısında (filo) ve faaliyetlere ilişkin harcamalarda meydana gelen negatif yönlü değişimin etkinlik düzeylerini azalttığını göstermektedir. Buna ek olarak bulgular, taşınan toplam yolcu sayısı, doluluk oranı ve toplam gelir değişkenlerinde meydana gelen pozitif yönlü artışın, teknik ve ölçek etkinlik düzeyini arttırdığını ortaya koymaktadır.

Analize dâhil edilen havayolu sayısı ve incelenen dönem dikkate alındığında bu çalışmanın havacılık alan yazınına ve havayolu şirketlerine önemli katkı sağlaması beklenmektedir. Çalışma kapsamında elde edilen bulgular, havayolu şirketlerinin yıllara göre etkinlik düzeylerinin incelenmesine ve etkinsizliğin nedenlerine dair önemli kanıtlar sunmaktadır. Dolayısıyla havayolu taşımacılığı paydaşlarının etkinsizliği azaltmaya ve etkinliği arttırmaya yönelik yöntemler geliştirmeleri, hem havacılık sisteminin gelişimine hem de küresel ekonomik refaha önemli katkılar sağlayabilir. 


\section{Eskişehir Osmangazi Üniversitesi IïB Dergisi}

\section{Kaynaklar}

Arjomandi, Amir; Seufert, Juergen Heinz (2014), “An Evaluation of the World's Major Airlines' Technical and Environmental Performance", Economic Modelling, Vol. 41: 133-144.

Assaf, Albert (2009), "Are U.S. Airlines Really in Crisis", Tourism Management, Vol. 30: 916-921.

Assaf, A. George; Josiassen, Alexander (2009), "The Operational Performance of UK Airlines: 2002-2007", Journal of Economic Studies, Vol.38 No.1: 5-16.

Atan, Murat (2003), “Türkiye Bankacılık Sektöründe Veri Zarflama Analizi ile Bilançoya Dayalı Mali Etkinlik ve Verimlilik Analizi", Ekonomik Yaklaşım, Vol.14 No.48: 171-86.

Barros, Carlos Pestana; Peypoch, Nicolas (2009), "An Evaluation of European Airlines Operational Performance", International Journal of Production Economics, Vol.122 No.2: 525-533.

Barbot, Cristina; Álvaro, Costa; Sochirca, Elena (2008), "Airlines Performance in the New Market Context: A Comparative Productivity", Journal of Air Transport Management, Vol.14 No.5: 270-274.

Bhadra, Dipasis (2009), "Race to the Bottom or Swimming Upstream: Performance Analysis of US Airlines", Journal of Air Transport Management, Vol. 15 No.5: 227-235.

Capobianco, Heloisa Márcia Pires; Fernandes, Elton (2004), "Capital Structure in the World Airline Industry", Transportation Research Part A , Vol.38 No.6: 421-434.

Chiou, Yu-Chiun; Chen, Yen-Heng (2006), “Route-based Performance Evaluation of Taiwanese Domestic Airlines Using Data Envelopment Analysis", Transportation Research Part E, Vol.42 No.2: 116-127.

Cook, Wade D; Kress, Moshe; Seiford, Lawrence (1996), "Data Envelopment Analysis in the Presence of both Quantitative and Qualitative Factors", Journal of the Operational Research Society, Vol.47 No.7: 945-953.

Cooper, William Wade; Seiford, Lawrence M; Tone, Kaoru (2007), “Data Envelopment Analysis: A Comprehensive Text with Models, Applications, References and DEA-Solver Software", Newyork: Springer.

Ertuğrul, İrfan; Işık Tut, Ayşegül (2008), “işletmelerin VZA ile Mali Tablolarına Dayalı Etkinlik Ölçümü: Metal Ana Sanayiinde Bir Uygulama”, Afyon Kocatepe Üniversitesi Iktisadi ve Idari Bilimler Fakültesi Dergisi, Vol.10 No.1: 201217.

Fethi, Meryem Duygun; Jackson, Peter; Weyman-Jones, G. Thomas (2000), "Measuring the Efficiency of European Airlines: an Application of DEA and Tobit Analysis. Leicester: Efficiency and Productivity Research Unit", University of Leicester. 1-32.

Girginer, Nuray; Yalam, Abdullah; Kaygisiz, Zeliha (2007), "Veri zarflama analizi ve kümeleme analizi ile Türkiye sigortacılık sektöründeki firmaların performanslarının karşılaştırılması", iktisat işletme ve Finans, Vol.22 No.261: 100-113.

Good, H. David; Röller, Lars-Hendrik; Sickles; C. Robin (1995), “Airline Efficiency Differences Between Europe and the US: Implications for the Pace of EC Integration And Domestic Regulation", European Journal of Operational Research, Vol.80 No.1: 508-518.

Gramani, Maria N. Cristina (2012), "Efficiency Decomposition Approach: A Cross-Country Airline Analysis", Expert Systems with Applications, Vol.39 No.5: 5815-5819.

Greer, Mark (2009), "is it the Labor Unions' Fault? Dissecting the Causes of the Impaired Technical Efficiencies of the Legacy Carriers in the United States", Transportation Research Part A, Vol.43 No.9-10: 779-789.

Gujarati, N. Damodar (2004), “Basic Econometrics”, Tata, McGraw-Hill Education.

Hong, Seockjin; Zhang, Anming (2010), “An Efficiency Study of Airlines and Air Cargo/Passenger Divisions: A DEA Approach", World Review of Intermodal Transportation Research, Vol.3 No.1: 137-149.

Hooper, Paul (1997), "Liberalising Competition in Domestic Airline Markets in Asia-The Problematic Interface Between Domestic and International Regulatory Policies", Transportation Research Part E: Logistics and Transportation Review, Vol.33 No.3: 197-209.

Kaplan, Muhittin; Çelik, Tuncay (2007), "Türk Sigortacilik Sektöründe Etkinlik ve Etkinliği Belirleyen Faktörler", iktisat işletme ve Finans, Vol.22 No.253: 97-114.

Karsak, Eyüp Ertuğrul; İşcan, Firuzan (2000), “Çimento Sektöründe Göreli Faaliyet Performanslarının Ağılık Kısıtlamaları Ve Çapraz Etkinlik Kullanılarak Veri Zarflama Analizi İle Değerlendirilmesi”, Endüstri Mühendisliği Dergisi, Vol.2, No.3: 2-10. 
Kayalıdere, Koray; Kargın, Sibel (2004), "Çimento ve Tekstil Sektörlerinde Etkinlik Çalışması ve Veri Zarflama Analizi”, Dokuz Eylül Üniversitesi Sosyal Bilimler Dergisi, Vol. 6, No.3: 196-219.

Köse, Tunç; Uçkun, Nurullah; Girginer, Nuray (2014), "An Efficiency Analysis of the Clinical Departments of A Public Hospital in Eskisehir By Using DEA", Global Journal on Advance in Pure \& Applied Sciences, Vol.4, No.1: 252-258.

Lee, Boon; Worthington, Andrew (2014), "Technical Efficiency of Mainstream Airlines and Low-Cost Carriers: New Evidence Using Bootstrap Data Envelopment Analysis Truncated Regression”, Journal of Air Transport Management, Vol.38, No. 5: 15-20.

Lorcu, Fatma (2008), “Veri Zarflama Analizi (Dea) ile Türkiye ve Avrupa Birliği Ülkelerinin Sağlık Alanındaki Etkinliklerinin Değerlendirilmesi", Yayınlanmamış Doktora Tezi, İstanbul: İstanbul Üniversitesi.

Lu, Wen-Min; Wang, Wei-Kang; Hung, Shiu-Wan; Lu, En-Tzu (2012), "The Effects of Corporate Governance on Airline Performance: Production and Marketing Efficiency Perspectives", Transportation Research Part E, Vol.48, No.2: 529-544.

Merkert, Rico; Hensher, David (2011), "The İmpact of Strategic Management and Fleet Planning on Airline Efficiency A Random Effects Tobit Model Based on DEA Efficiency Scores", Transportation Research Part A, Vol.45, No.7: 686-695.

Ouellette, Pierre; Petit, Patrick; Tessier- Parent, Louis-Philippe; Vigeant, Stephane (2010), "Introducing Regulation in the Measurement of Efficiency, with An Application to the Canadian Air Carriers Industry", European Journal of Operational Research, Vol.200, No.1: 216-226.

Özden, Ünal Halit (2008) "Veri Zarflama Analizi (VZA) ile Türkiye'deki Vakıf Üniversitelerinin Etkinliğinin Ölçülmesi", Istanbul University Journal of the School of Business, Vol. 37, No.2: 167-185.

Öztürk, Oğuzhan; Girginer, Nuray (2015), "The Export Efficiency of Turkish Textile and Apparel Firms: An Investigation Employing Data Envelopment Analysis (DEA) and Analytic Hierarchy Process (AHP) Methods", Journal of Textile \& Apparel/Tekstil ve Konfeksiyon, Vol.25, No.1: 10-23.

Ramanathan, Ram (2003), "An Introduction to Data Envelopment Analysis A Tool For Performance Measurement", New Delhi: Sage Publications.

Saranga, Haritha; Nagpal, Rajiv (2016), "Drivers of Operational Efficiency and its Impact on Market Performance in The Indian Airline Industry", Journal of Air Transport Management, Vol.53, No.4: 165-176.

Schefczyk, Michael (1993), "Operational Performance of Airlines: An Extension of Traditional Measurment Paradigms", Strategic Management Journal, Vol.14, No.4: 301-317.

Sheraga, Carl (2004), "Operational Efficiency Versus Financial Mobility in The Global Airline Industry: A Data Envelopment and Tobit Analysis", Transportation Research Part A, Vol.38, No.5: 383-404.

Sengül, Ümran; Eslamian, Seyedhadi; Eren, Miraç (2013), "Türkiye'de İstatistiki Bölge Birimleri Sınıflamasına Göre Düzey 2 Bölgelerinin Ekonomik Etkinliklerinin VZA Yöntemi İle Belirlenmesi ve Tobit Model Uygulaması", Çanakkale Onsekiz Mart Üniversitesi Yönetim Bilimleri Dergisi, Vol.11, No.21: 75-99.

Tavassoli, Mohammad; Faramarzi, Gholam Reza; Saen, Reza Farzipoor (2014), "Efficiency and Effectiveness in Airline Performance Using A SBM-NDEA Model in the Presence of Shared Input", Journal of Air Transport Management, Vol.34, No.1: 146-153.

Tütek, Hülya; Gümüşoğlu, Şevkinaz; Özdemir, Aslı (2012), “Sayısal Yöntemler: Yönetsel Yaklaşım”, İstanbul: Beta.

Üçdoğruk, Şenay; Fahamet, Akın; Hamdi, Emeç (2001), "Türkiye Hanehalkı Eğlence Kültür Harcamalarında Tobit Modelin Kullanımı", iktisadi ve Idari Bilimler Fakültesi Dergisi, Vol.3, No.3: 13-26.

Ulucan, Aydın (2002), “iso 500 Şirketlerinin Etkinliklerinin Ölçülmesinde Veri Zarflama Analizi: Farklı Girdi Çıktı Bileşenleri ve Ölçeğe Göre Getiri Yaklaşımları ile Değerlendirmeler", Ankara Üniversitesi SBF Dergisi, Vol.57, No.2: 185202.

Vasigh, Bazargan (2015). "Foundations Of Airline Finance: Methodology and Practice”, New York: Routledge, Taylor \& Francis Group.

Yalama, Abdullah; Sayım, Mustafa (2008), "Veri Zarflama Analizi Ile İmalat Sektörünün Performans Değerlendirmesi”, Dokuz Eylül Üniversitesi Iktisadi ve Idari Bilimler Fakültesi Dergisi, Vol:23, No.1: 89-107

Yalçıner, Kürşat; Atan, Murat; Boztosun, Derviş (2005), "Finansal Oranlarla Hisse Senedi Getirileri Arasındaki iliş̧ki”, Muhasebe ve Finansman Dergisi, Vol.27, No.1: 1-12.

Yolalan, Reha (1993), “İşletmeler Arası Göreli Etkinlik Ölçümü”, Ankara: Milli Prodüktivite Merkezi Yayınları. 


\section{Eskişehir Osmangazi Üniversitesi IïB Dergisi}

Yu, Ming.-Miin; Chang, Yu-Chun; Chen, Li.-Hsueh (2016), “Measurement Of Airlines' Capacity Utilization and Cost Gap: Evidence From Low-Cost Carriers", Journal of Air Transport Management, Vol.53, No.4: 186-198.

Zhu, Joe (2011), "Airlines Performance Via Two-Stage Network DEA Approach", Journal of CENTRUM Cathedra, Vol.4, No.2: 260-269. 
EK 1 - Çalışmaya dâhil edilen havayolları ve IATA kodları

\begin{tabular}{llllll}
\hline KOD & HAVAYOLU & KOD & HAVAYOLU & KOD & HAVAYOLU \\
\hline EI & AER LINGUS & MU & CHINA EASTERN & LA & LATAM AIRLINES \\
SU & AEROFLOT & CZ & CHINA SOUTHERN & LH & LUFTHANSA \\
AM & AEROMEXICO & CM & COPA HOLDINGS & D8 & NORWEGIAN AIR \\
AB & AIR BERLIN & DL & DELTA AIR LINES & QF & QANTAS AIRWAYS \\
AC & AIR CANADA & U2 & EASYJET & FR & RYANAIR \\
CA & AIR CHINA & LY & EL AL & SK & SAS \\
AF/KL & AIR FRANCE - KLM & BR & EVA AIRWAYS & SC & SHANDONG AIRLINES \\
NZ & AIR NEW ZEALAND & AY & FINNAIR & SQ & SINGAPORE AIRLINES \\
AK & AIRASIA & GA & GARUDA INDONESIA & OO & SKYWEST \\
AS & ALASKA AIR & G3 & GOL LINHAS & WN & SOUTHWEST AIRLINES \\
NH & ANA HOLDINGS & HU & HAINAN AIRLINES & TG & THAI AIRWAYS \\
OZ & ASIANA AIRLINES & HA & HAWAIIAN AIRLINES & TK & TURK HAVA YOLLARI \\
AV & AVIANCA & QJ & JET AIRWAYS & UA & UNITED CONTINENTAL \\
CX & CATHAY PACIFIC & B6 & JETBLUE AIRWAYS & VA & VIRGIN AUSTRALIA \\
CI & CHINA AIRLINES & KE & KOREAN AIR LINES & WS & WESTJET AIRLINES \\
\hline
\end{tabular}


Eskişehir Osmangazi Üniversitesi IißBF Dergisi

EK 2 - Etkin Olmayan Havayolları ve Referans Değerleri Kümesi (2010-2016)

\begin{tabular}{|c|c|c|}
\hline \multicolumn{3}{|c|}{2010} \\
\hline & CCR & $\mathrm{BCC}$ \\
\hline $\mathrm{El}$ & $12(0.09) 27(0.47) 33(0.40)$ & 0 \\
\hline SU & $14(0.14) 20(0.08) 27(0.56) 35(0.09) 43(0.03)$ & $14(0.14) 20(0.06) 27(0.68) 35(0.09) 43(0.03)$ \\
\hline AM & $9(0.12) 11(0.02) 13(0.04) 20(0.01) 27(0.55) 31(0.21)$ & $9(0.10) 11(0.02) 13(0.01) 27(0.68) 31(0.19)$ \\
\hline$A B$ & 0 & 0 \\
\hline $\mathrm{AC}$ & $12(0.21) 14(0.41) 20(0.45) 43(0.08)$ & $14(0.47) 20(0.39) 30(0.07) 43(0.08)$ \\
\hline $\mathrm{CA}$ & $12(1.25) 20(0.60) 43(0.12)$ & 0 \\
\hline $\begin{array}{c}\mathrm{AF} / \mathrm{K} \\
\mathrm{L}\end{array}$ & $14(0.12) 27(0.04) 32(0.70) 43(0.14)$ & $14(0.11) 21(0.05) 32(0.70) 43(0.14)$ \\
\hline $\mathrm{NZ}$ & 0 & 0 \\
\hline $\mathrm{AK}$ & 3 & 4 \\
\hline AS & $20(0.28) 27(0.64) 43(0.05)$ & $20(0.27) 27(0.68) 43(0.05)$ \\
\hline $\mathrm{NH}$ & 5 & 5 \\
\hline $\mathrm{OZ}$ & 5 & 1 \\
\hline AV & 1 & 1 \\
\hline $\mathrm{CX}$ & 10 & 9 \\
\hline $\mathrm{Cl}$ & $14(0.13) 27(0.77) 43(0.05)$ & $14(0.13) 27(0.82) 32(0.01) 43(0.04)$ \\
\hline $\mathrm{MU}$ & $20(0.68) 25(0.28) 31(1.16) 43(0.05)$ & $11(0.03) 32(0.14) 34(0.14) 35(0.67) 43(0.02)$ \\
\hline $\mathrm{CZ}$ & $20(0.11) 31(1.25) 35(0.64) 43(0.06)$ & $19(0.09) 32(0.08) 34(0.05) 35(0.74) 43(0.05)$ \\
\hline $\mathrm{CM}$ & 0 & 0 \\
\hline $\mathrm{DL}$ & $14(1.57) 31(0.27) 35(1.49) 43(0.16)$ & 2 \\
\hline $\mathrm{U} 2$ & 14 & 10 \\
\hline LY & 0 & 3 \\
\hline BR & $12(0.03) 14(0.06) 27(0.81) 32(0.03) 43(0.01)$ & $11(0.02) 14(0.05) 21(0.23) 27(0.67) 32(0.02) 43(0.01)$ \\
\hline AY & $12(0.04) 20(0.03) 27(0.72) 36(0.09) 43(0.03)$ & $12(0.06) 20(0.01) 27(0.80) 36(0.10) 43(0.02)$ \\
\hline GA & $20(0.14) 27(0.54) 33(0.10) 35(0.02) 43(0.01)$ & $20(0.09) 27(0.62) 33(0.26) 35(0.02) 43(0.01)$ \\
\hline G3 & 1 & 0 \\
\hline $\mathrm{HU}$ & 0 & 0 \\
\hline $\mathrm{HA}$ & 15 & 12 \\
\hline QJ & $14(0.04) 20(0.07) 27(0.72) 35(0.06) 43(0.02)$ & $14(0.04) 20(0.06) 27(0.82) 35(0.06) 43(0.02)$ \\
\hline B6 & $20(0.43) 27(0.33) 35(0.17) 43(0.02)$ & $20(0.42) 27(0.40) 35(0.17) 43(0.02)$ \\
\hline KE & 0 & 1 \\
\hline LA & 6 & 3 \\
\hline LH & 4 & 6 \\
\hline D8 & 2 & 2 \\
\hline QF & 1 & 3 \\
\hline FR & 9 & 10 \\
\hline SK & 1 & 1 \\
\hline SC & 0 & 0 \\
\hline SQ & $14(0.79) 27(0.10) 32(0.03) 43(0.02)$ & $11(0.01) 14(0.78) 21(0.17) 32(0.03) 43(0.01)$ \\
\hline $\mathrm{OO}$ & 0 & 0 \\
\hline WN & $35(1.11) 43(0.20)$ & $19(0.19) 35(0.74) 43(0.07)$ \\
\hline TG & $9(0.73) 14(0.44)$ & $9(0.52) 14(0.44) 35(0.04)$ \\
\hline TK & $\begin{array}{c}14(0.10) 20(0.35) 27(0.06) 31(0.33) 35(0.02) 43 \\
(0.04)\end{array}$ & $\begin{array}{c}9(0.00) 14(0.08) 20(0.33) 27(0.19) 31(0.34) 35(0.02) 43 \\
(0.03)\end{array}$ \\
\hline UA & 19 & 17 \\
\hline VA & $\begin{array}{c}9(0.09) 11(0.01) 20(0.19) 27(0.58) 31(0.01) 34 \\
(0.05)\end{array}$ & $\begin{array}{c}9(0.11) 11(0.01) 20(0.18) 27(0.65) 31(0.00) 34(0.05) 43 \\
(0.00)\end{array}$ \\
\hline WS & $20(0.04) 27(0.78) 35(0.09) 43(0.03)$ & $20(0.02) 27(0.82) 33(0.04) 35(0.09) 43(0.03)$ \\
\hline
\end{tabular}


Nisan 2019, C. 14, S. 1

\begin{tabular}{|c|c|c|}
\hline \multicolumn{3}{|c|}{2011} \\
\hline & CCR & BCC \\
\hline $\mathrm{El}$ & 1 & 1 \\
\hline SU & $14(0.112) 13(0.283) 7(0.015) 20(0.392) 8(0.219)$ & $14(0.143) 20(0.319) 26(0.317) 27(0.205) 32(0.016)$ \\
\hline $\mathrm{AM}$ & $31(0.053) 13(0.155) 9(0.255) 8(0.501)$ & $9(0.248) 27(0.018) 13(0.160) 8(0.574)$ \\
\hline$A B$ & 4 & 4 \\
\hline $\mathrm{AC}$ & $14(0.470) 7(0.066) 43(0.020) 20(0.579)$ & $14(0.456) 7(0.040) 43(0.036) 19(0.033) 20(0.434)$ \\
\hline CA & 6 & 6 \\
\hline $\mathrm{AF} / \mathrm{KL}$ & 7 & 7 \\
\hline $\mathrm{NZ}$ & 8 & 8 \\
\hline AK & 9 & 9 \\
\hline AS & $27(0.162) 13(0.399) \quad 20(0.468)$ & $26(0.502) 27(0.134) 43(0.001) 20(0.362) 32(0.001)$ \\
\hline $\mathrm{NH}$ & 11 & 11 \\
\hline $\mathrm{OZ}$ & 12 & 12 \\
\hline AV & 13 & 13 \\
\hline$C X$ & 14 & 14 \\
\hline $\mathrm{Cl}$ & $13(0.06) 20(0.07) 14(0.02) 7(0.03) 8(0.8)$ & $27(0.21) 7(0.04) 20(0.06) 13(0.021) 14(0.045) 8(0.61)$ \\
\hline $\mathrm{MU}$ & $9(0.7) 31(1.09) 13(0.39) 34(0.16) 20(0.4)$ & 16 \\
\hline $\mathrm{CZ}$ & $20(1.218) \quad 13(0.616) 43(0.125) 7(0.032)$ & $35(0.242) 20(0.459) \quad 32(0.013) 19(0.042) 40(0.027) 35(0.217)$ \\
\hline $\mathrm{CM}$ & $35(0.006) 13(0.191) 9(0.519) 37(0.268)$ & $35(0.002) 13(0.185) 9(0.534) 37(0.280)$ \\
\hline $\mathrm{DL}$ & $9(2.192) 20(1.869) 13(0.282) 14(1.672)$ & 19 \\
\hline U2 & 20 & 20 \\
\hline $\mathrm{LY}$ & 21 & 21 \\
\hline BR & $14(0.015) 8(0.200) 27(0.71) 7(0.046) 20(0.01)$ & $7(0.046) 20(0.015) 8(0.196) 14(0.015) 27(0.728)$ \\
\hline AY & $27(0.7) 7(0.01) 26(0.08) 14(0.052) 20(0.03)$ & $27(0.806) 7(0.017) 14(0.052) 20(0.035) 26(0.090)$ \\
\hline GA & $20(0.063) 33(0.340) 4(0.05) 27(0.05) 26(0.49)$ & $20(0.095) 30(0.017) 27(0.117) 33(0.297) 26(0.474)$ \\
\hline G3 & 25 & 25 \\
\hline $\mathrm{HU}$ & 26 & 26 \\
\hline $\mathrm{HA}$ & 27 & 27 \\
\hline QJ & $27(0.41) 13(0.06) 9(0.230) 14(0.06) 20(0.23)$ & $27(0.45) 26(0.06) 13(0.02) 20(0.24) 38(0.05) 9(0.15)$ \\
\hline B6 & $9(0.160) 35(0.083) 13(0.124) 20(0.636)$ & $9(0.15) 26(0.09) 20(0.6) 35(0.09) 13(0.05)$ \\
\hline $\mathrm{KE}$ & 30 & 30 \\
\hline LA & 31 & 31 \\
\hline LH & 32 & 32 \\
\hline D8 & 33 & 33 \\
\hline QF & 34 & 34 \\
\hline $\mathrm{FR}$ & 35 & 35 \\
\hline SK & 36 & 36 \\
\hline SC & 37 & 37 \\
\hline SQ & 38 & 38 \\
\hline 00 & 39 & 39 \\
\hline WN & $13(0.565) 35(0.358) 20(2.250)$ & 40 \\
\hline TG & $9(0.649) 38(0.496)$ & $9(0.464) 35(0.033) 38(0.503)$ \\
\hline TK & $13(0.3) 14(0.3) 20(0.19) 9(0.53) 38(0.04) 35(0.08)$ & $14(0.15) 13(0.28) 35(0.12) 38(0.149) 20(0.267)$ \\
\hline UA & 43 & 43 \\
\hline VA & $26(0.1) 7(0.1) 20(0.23) 27(0.62) 14(0.03)$ & $14(0.01) 27(0.69) 6(0.02) 20(0.25) 7(0.01)$ \\
\hline WS & $20(0.25) 13(0.04) 26(0.24) 37(0.17) 27(0.29)$ & $26(0.311) 35(0.003) 27(0.459) 20(0.226)$ \\
\hline
\end{tabular}


Eskişehir Osmangazi Üniversitesi iïB Dergisi

\begin{tabular}{|c|c|c|}
\hline \multicolumn{3}{|c|}{2012} \\
\hline & CCR & BCC \\
\hline El & 2 & 3 \\
\hline SU & $6(0.35) 9(0.06) 13(0.06) 23(0.45) 31(0.05) 38(0.02)$ & $6(0.34) 9(0.06) 13(0.06) 23(0.47) 31(0.05) 38(0.01)$ \\
\hline AM & $8(0.48) 9(0.34) 27(0.07) 31(0.04)$ & $1(0.15) 8(0.54) 9(0.29) 31(0.02)$ \\
\hline$A B$ & 0 & 0 \\
\hline $\mathrm{AC}$ & $6(0.30) 9(0.66) 34(0.04) 38(0.45)$ & $6(0.18) 19(0.03) 20(0.26) 31(0.06) 34(0.01) 38(0.45)$ \\
\hline $\mathrm{CA}$ & 9 & 3 \\
\hline $\mathrm{AF} / \mathrm{KL}$ & $31(1.16) 34(1.02) 38(0.08)$ & 0 \\
\hline NZ & 1 & 1 \\
\hline AK & 19 & 11 \\
\hline AS & $6(0.09) 9(0.97) 26(0.19) 31(0.05) 35(0.01)$ & 0 \\
\hline $\mathrm{NH}$ & 1 & 1 \\
\hline $\mathrm{OZ}$ & $11(0.03) 20(0.02) 23(0.54) 30(0.13) 33(0.24) 34(0.05)$ & $11(0.03) 20(0.02) 23(0.54) 30(0.13) 33(0.24) 34(0.05)$ \\
\hline AV & 3 & 4 \\
\hline$C X$ & $9(0.41) 31(0.11) 34(0.04) 38(0.82)$ & 0 \\
\hline $\mathrm{Cl}$ & $9(0.49) 21(0.21) 31(0.12) 38(0.13)$ & $9(0.47) 21(0.29) 31(0.12) 38(0.13)$ \\
\hline MU & $9(2.63) 31(0.67) 38(0.22)$ & 0 \\
\hline $\mathrm{CZ}$ & $9(3.03) 26(0.25) 31(0.72)$ & $19(0.18) 31(0.56) 35(0.25)$ \\
\hline $\mathrm{CM}$ & $1(0.31) 9(0.41) 13(0.22) 35(0.01)$ & $1(0.32) 9(0.47) 13(0.21)$ \\
\hline $\mathrm{DL}$ & $6(0.70) 9(3.50) 20(0.68) 38(1.27)$ & 3 \\
\hline U2 & 4 & 5 \\
\hline LY & 3 & 3 \\
\hline $\mathrm{BR}$ & $9(0.29) 21(0.53) 31(0.07) 34(0.04) 38(0.04)$ & $9(0.28) 21(0.58) 31(0.07) 34(0.04) 38(0.03)$ \\
\hline AY & 4 & 3 \\
\hline GA & $9(0.61) 13(0.01) 26(0.26) 31(0.09)$ & $9(0.60) 13(0.01) 26(0.25) 31(0.09) 37(0.05)$ \\
\hline G3 & 0 & 0 \\
\hline $\mathrm{HU}$ & 7 & 3 \\
\hline $\mathrm{HA}$ & 1 & 1 \\
\hline QJ & $9(0.84) 21(0.01) 31(0.06) 38(0.08)$ & $9(0.83) 21(0.03) 31(0.06) 38(0.08)$ \\
\hline B6 & $6(0.08) 9(1.56) 20(0.03) 26(0.11) 35(0.06)$ & $9(0.31) 20(0.57) 31(0.03) 35(0.08)$ \\
\hline KE & 1 & 1 \\
\hline LA & 13 & 10 \\
\hline LH & 0 & 0 \\
\hline D8 & 2 & 1 \\
\hline QF & 7 & 4 \\
\hline $\mathrm{FR}$ & 5 & 4 \\
\hline SK & 0 & 0 \\
\hline SC & 0 & 1 \\
\hline SQ & 11 & 7 \\
\hline $\mathrm{OO}$ & 0 & 0 \\
\hline WN & $9(3.34) 20(0.81) 26(1.34) 31(0.03)$ & 0 \\
\hline TG & 0 & 0 \\
\hline TK & $6(0.12) 9(0.54) 31(0.06) 35(0.24) 38(0.26)$ & $9(0.08) 19(0.00) 20(0.31) 31(0.12) 35(0.21) 38(0.28)$ \\
\hline UA & $6(0.44) 9(5.43) 34(0.79) 38(0.67)$ & 0 \\
\hline VA & $1(0.32) 6(0.14) 9(0.45) 23(0.05) 26(0.01) 34(0.02)$ & $1(0.35) 6(0.14) 9(0.44) 23(0.04) 26(0.01) 34(0.02)$ \\
\hline WS & $6(0.03) 9(0.43) 23(0.09) 26(0.30) 33(0.14) 35(0.04)$ & $9(0.23) 13(0.00) 20(0.07) 26(0.39) 27(0.27) 35(0.03) 38(0.01)$ \\
\hline
\end{tabular}


Nisan 2019, C. 14, S. 1

\begin{tabular}{|c|c|c|}
\hline \multicolumn{3}{|c|}{2013} \\
\hline & CCR & BCC \\
\hline $\mathrm{El}$ & 5 & 5 \\
\hline SU & $8(0.07) 20(0.41) 21(0.02) 27(0.04) 34(0.32) 38(0.07)$ & $20(0.39) 21(0.09) 23(0.03) 27(0.11) 34(0.33) 38(0.05)$ \\
\hline AM & $1(0.14) 8(0.53) 9(0.18) 13(0.06) 20(0.03)$ & $1(0.20) 8(0.50) 9(0.21) 13(0.09)$ \\
\hline$A B$ & 1 & 0 \\
\hline $\mathrm{AC}$ & $8(0.55) 20(0.31) 34(0.12) 38(0.49)$ & $14(0.04) 19(0.03) 20(0.28) 34(0.13) 38(0.51)$ \\
\hline $\mathrm{CA}$ & 1 & 1 \\
\hline $\mathrm{AF} / \mathrm{KL}$ & 0 & 0 \\
\hline NZ & 9 & 3 \\
\hline $\mathrm{AK}$ & 5 & 5 \\
\hline AS & 2 & 1 \\
\hline $\mathrm{NH}$ & 0 & 0 \\
\hline $\mathrm{OZ}$ & $1(0.27) 6(0.09) 20(0.05) 23(0.41) 34(0.10)$ & $1(0.36) 6(0.09) 20(0.03) 23(0.42) 34(0.09)$ \\
\hline AV & 2 & 2 \\
\hline $\mathrm{CX}$ & 2 & 2 \\
\hline $\mathrm{Cl}$ & $8(0.60) 14(0.06) 20(0.12) 21(0.11) 34(0.02)$ & $8(0.54) 14(0.05) 20(0.11) 21(0.27) 34(0.03)$ \\
\hline $\mathrm{MU}$ & $4(1.60) 8(0.71) 20(0.26) 31(0.12)$ & 0 \\
\hline $\mathrm{CZ}$ & $20(1.32) 34(0.45)$ & $19(0.21) 20(0.50) 34(0.29)$ \\
\hline $\mathrm{CM}$ & 1 & 1 \\
\hline $\mathrm{DL}$ & $8(4.62) 20(2.40) 34(0.19) 38(0.10)$ & 3 \\
\hline $\mathrm{U} 2$ & 18 & 13 \\
\hline LY & 5 & 4 \\
\hline $\mathrm{BR}$ & $8(0.31) 20(0.11) 21(0.47) 31(0.06)$ & $8(0.17) 20(0.11) 21(0.65) 31(0.08)$ \\
\hline AY & 1 & 2 \\
\hline GA & $1(0.05) 9(0.06) 20(0.12) 26(0.47) 31(0.01) 37(0.17)$ & $1(0.20) 9(0.02) 20(0.11) 26(0.43) 31(0.00) 37(0.24)$ \\
\hline G3 & $9(0.11) 13(0.09) 20(0.49) 37(0.11)$ & $9(0.25) 13(0.13) 20(0.40) 37(0.22)$ \\
\hline $\mathrm{HU}$ & 3 & 3 \\
\hline $\mathrm{HA}$ & 2 & 2 \\
\hline QJ & $20(0.18) 21(0.60) 27(0.11) 35(0.03) 38(0.01)$ & $20(0.19) 21(0.43) 27(0.38) 38(0.01)$ \\
\hline B6 & $9(0.16) 20(0.75) 35(0.03)$ & $9(0.24) 20(0.75) 35(0.01)$ \\
\hline $\mathrm{KE}$ & 0 & 0 \\
\hline LA & 3 & 2 \\
\hline $\mathrm{LH}$ & 0 & 0 \\
\hline D8 & 0 & 0 \\
\hline QF & 9 & 6 \\
\hline $\mathrm{FR}$ & 2 & 2 \\
\hline SK & 0 & 0 \\
\hline SC & 2 & 2 \\
\hline SQ & 5 & 4 \\
\hline $\mathrm{OO}$ & 0 & 0 \\
\hline WN & $10(0.93) 20(1.88) 34(0.03)$ & 0 \\
\hline TG & 0 & 0 \\
\hline TK & $8(0.03) 20(0.95) 38(0.29)$ & $19(0.06) 20(0.62) 35(0.08) 38(0.24)$ \\
\hline UA & $8(3.96) 14(0.19) 20(1.75) 34(0.57)$ & 0 \\
\hline VA & $1(0.22) 18(0.40) 20(0.21) 26(0.03) 34(0.07)$ & $1(0.32) 18(0.40) 20(0.19) 26(0.02) 34(0.07)$ \\
\hline WS & $1(0.22) 9(0.25) 10(0.17) 20(0.13) 21(0.03) 26(0.19)$ & $1(0.29) 9(0.24) 10(0.17) 20(0.13) 26(0.17)$ \\
\hline
\end{tabular}


Eskişehir Osmangazi Üniversitesi iïB Dergisi

\begin{tabular}{|c|c|c|}
\hline \multicolumn{3}{|c|}{2014} \\
\hline & CCR & BCC \\
\hline $\mathrm{El}$ & 3 & 4 \\
\hline SU & $8(0.15) 14(0.33) 20(0.41)$ & $8(0.31) 14(0.30) 20(0.39)$ \\
\hline $\mathrm{AM}$ & 10 & 5 \\
\hline$A B$ & 2 & 0 \\
\hline $\mathrm{AC}$ & $3(0.38) 4(0.02) 20(0.21) 35(0.06) 38(0.68)$ & 0 \\
\hline $\mathrm{CA}$ & 0 & 0 \\
\hline $\mathrm{AF} / \mathrm{KL}$ & 1 & 1 \\
\hline NZ & 5 & 4 \\
\hline AK & 1 & 1 \\
\hline AS & $3(0.41) 20(0.32) 21(0.13) 26(0.16)$ & 0 \\
\hline $\mathrm{NH}$ & $20(0.46) 32(0.12) 34(0.52)$ & 0 \\
\hline $\mathrm{OZ}$ & $1(0.33) 20(0.06) 23(0.27) 30(0.16) 34(0.13)$ & $1(0.38) 20(0.06) 23(0.29) 30(0.15) 34(0.13)$ \\
\hline $\mathrm{AV}$ & 0 & 0 \\
\hline$C X$ & 5 & 4 \\
\hline $\mathrm{Cl}$ & $7(0.00) 8(0.54) 14(0.07) 20(0.11) 23(0.19)$ & $7(0.00) 8(0.60) 14(0.05) 20(0.11) 23(0.24)$ \\
\hline $\mathrm{MU}$ & $4(0.15) 8(1.11) 31(0.50) 35(0.54)$ & $31(0.01) 32(0.26) 35(0.70) 38(0.04)$ \\
\hline $\mathrm{CZ}$ & $3(3.67) 20(0.03) 35(0.23)$ & $20(0.39) 31(0.19) 40(0.19) 43(0.22)$ \\
\hline $\mathrm{CM}$ & $3(0.31) 9(0.28) 27(0.37) 35(0.01)$ & $1(0.06) 3(0.31) 9(0.33) 27(0.29)$ \\
\hline $\mathrm{DL}$ & $3(0.16) 14(1.20) 20(2.41) 34(0.37)$ & 0 \\
\hline U2 & 17 & 11 \\
\hline LY & 4 & 2 \\
\hline $\mathrm{BR}$ & $8(0.84) 14(0.02) 20(0.06)$ & $8(0.95) 14(0.00) 20(0.05)$ \\
\hline $\mathrm{AY}$ & 2 & 2 \\
\hline GA & $1(0.39) 20(0.19) 21(0.07) 26(0.12) 31(0.07)$ & $1(0.71) 3(0.01) 20(0.21) 31(0.07)$ \\
\hline G3 & 0 & 0 \\
\hline $\mathrm{HU}$ & 2 & 0 \\
\hline $\mathrm{HA}$ & 3 & 3 \\
\hline QJ & $20(0.27) 21(0.69) 35(0.02)$ & $20(0.25) 21(0.73) 35(0.02)$ \\
\hline B6 & $3(0.15) 20(0.52) 27(0.17) 35(0.12)$ & $3(0.14) 20(0.51) 27(0.23) 35(0.12)$ \\
\hline $\mathrm{KE}$ & 1 & 1 \\
\hline LA & 3 & 5 \\
\hline LH & 1 & 1 \\
\hline D8 & 0 & 0 \\
\hline QF & 4 & 1 \\
\hline $\mathrm{FR}$ & 9 & 5 \\
\hline SK & 0 & 0 \\
\hline SC & 0 & 0 \\
\hline SQ & 2 & 1 \\
\hline $\mathrm{OO}$ & 0 & 0 \\
\hline WN & $3(1.42) 20(1.45) 35(0.22)$ & 1 \\
\hline TG & 0 & 0 \\
\hline TK & $3(0.60) 20(0.20) 35(0.31) 38(0.40)$ & $3(0.04) 14(0.41) 20(0.13) 31(0.02) 35(0.36) 43(0.04)$ \\
\hline UA & $3(1.93) 14(0.41) 20(1.85) 34(0.79)$ & 2 \\
\hline VA & $1(0.14) 8(0.11) 20(0.25) 21(0.37) 31(0.04)$ & $1(0.22) 8(0.07) 20(0.24) 21(0.43) 31(0.04)$ \\
\hline WS & $3(0.13) 20(0.20) 27(0.64) 35(0.01)$ & $3(0.12) 20(0.19) 27(0.68) 35(0.01)$ \\
\hline
\end{tabular}


Nisan 2019, C. 14, S. 1

\begin{tabular}{|c|c|c|}
\hline \multicolumn{3}{|c|}{2015} \\
\hline & CCR & BCC \\
\hline El & 1 & 4 \\
\hline SU & $8(0.55) 14(0.17) 35(0.26) 41(0.10)$ & $5(0.13) 8(0.45) 14(0.11) 35(0.24) 41(0.06)$ \\
\hline AM & 3 & 3 \\
\hline$A B$ & 0 & 0 \\
\hline AC & $8(0.04) 12(0.08) 14(0.65) 34(0.03) 35(0.18)$ & $8(0.07) 12(0.09) 14(0.64) 34(0.02) 35(0.17)$ \\
\hline $\mathrm{CA}$ & 1 & 1 \\
\hline $\mathrm{AF} / \mathrm{KL}$ & 0 & 0 \\
\hline NZ & 16 & 10 \\
\hline $\mathrm{AK}$ & 2 & 2 \\
\hline AS & 3 & 2 \\
\hline $\mathrm{NH}$ & 0 & 0 \\
\hline $\mathrm{OZ}$ & 2 & 2 \\
\hline AV & $3(0.08) 8(0.52) 20(0.24) 31(0.02) 39(0.06)$ & $3(0.48) 8(0.11) 20(0.14) 32(0.01) 36(0.26)$ \\
\hline$C X$ & 6 & 5 \\
\hline $\mathrm{Cl}$ & $8(0.62) 14(0.06) 21(0.15) 31(0.03) 35(0.07)$ & $8(0.39) 14(0.08) 20(0.02) 21(0.44) 31(0.03) 35(0.05)$ \\
\hline $\mathrm{MU}$ & $8(1.80) 19(0.11) 20(0.49) 35(0.13)$ & $19(0.13) 20(0.05) 32(0.10) 34(0.22) 35(0.50)$ \\
\hline $\mathrm{CZ}$ & $8(0.34) 10(0.15) 19(0.37) 35(0.09)$ & $8(0.36) 10(0.18) 19(0.36) 35(0.09)$ \\
\hline $\mathrm{CM}$ & $8(0.01) 9(0.11) 27(0.76) 35(0.04)$ & $9(0.20) 21(0.07) 27(0.71) 35(0.02)$ \\
\hline $\mathrm{DL}$ & 4 & 4 \\
\hline U2 & 9 & 8 \\
\hline LY & 4 & 6 \\
\hline $\mathrm{BR}$ & $8(0.02) 14(0.15) 21(0.77) 35(0.02)$ & $8(0.04) 14(0.14) 21(0.79) 35(0.02)$ \\
\hline $\mathrm{AY}$ & 0 & 0 \\
\hline GA & $3(0.53) 8(0.04) 20(0.24) 31(0.01) 39(0.09)$ & $1(0.23) 3(0.43) 20(0.24) 31(0.01) 39(0.08)$ \\
\hline G3 & 0 & 0 \\
\hline $\mathrm{HU}$ & $8(0.45) 10(0.00) 20(0.34) 35(0.20)$ & $8(0.45) 20(0.33) 21(0.01) 35(0.20)$ \\
\hline $\mathrm{HA}$ & 2 & 2 \\
\hline QJ & $8(0.09) 20(0.01) 21(0.68) 31(0.03) 35(0.16)$ & $8(0.06) 20(0.02) 21(0.73) 31(0.03) 35(0.16)$ \\
\hline B6 & $10(0.54) 19(0.01) 20(0.32) 35(0.10)$ & $10(0.58) 19(0.00) 20(0.32) 35(0.10)$ \\
\hline $\mathrm{KE}$ & $6(0.25) 12(0.44) 34(0.15) 38(0.12)$ & $6(0.24) 12(0.50) 34(0.15) 35(0.00) 38(0.10)$ \\
\hline LA & 5 & 3 \\
\hline LH & 0 & 2 \\
\hline D8 & 0 & 0 \\
\hline QF & 4 & 4 \\
\hline $\mathrm{FR}$ & 13 & 13 \\
\hline SK & 0 & 2 \\
\hline SC & $1(0.46) 8(0.03) 9(0.32) 20(0.01) 39(0.11)$ & $1(0.56) 9(0.34) 39(0.10)$ \\
\hline SQ & 1 & 1 \\
\hline OO & 4 & 3 \\
\hline WN & $19(0.14) 20(1.69) 34(0.16)$ & 0 \\
\hline TG & 1 & 1 \\
\hline TK & $8(1.31) 14(0.20) 35(0.45)$ & $14(0.33) 19(0.02) 34(0.15) 35(0.50)$ \\
\hline UA & $8(0.57) 14(0.70) 34(1.48) 35(1.00)$ & 0 \\
\hline VA & $3(0.01) 8(0.70) 20(0.15) 31(0.00) 39(0.05)$ & $1(0.11) 3(0.10) 8(0.59) 20(0.12) 36(0.04) 39(0.03)$ \\
\hline WS & $8(0.31) 21(0.11) 27(0.44) 35(0.10)$ & $1(0.03) 8(0.26) 21(0.07) 27(0.54) 35(0.09)$ \\
\hline
\end{tabular}


Eskişehir Osmangazi Üniversitesi ïBBF Dergisi

\begin{tabular}{|c|c|c|}
\hline \multicolumn{3}{|c|}{2016} \\
\hline & CCR & BCC \\
\hline $\mathrm{EI}$ & 6 & 6 \\
\hline SU & $9(0.67) 10(0.00) 27(1.84) 35(0.24)$ & $5(0.23) 9(0.03) 10(0.35) 35(0.39)$ \\
\hline AM & 1 & 0 \\
\hline$A B$ & 0 & 0 \\
\hline $\mathrm{AC}$ & 1 & 3 \\
\hline $\mathrm{CA}$ & 2 & 1 \\
\hline $\mathrm{AF} / \mathrm{KL}$ & 4 & 4 \\
\hline NZ & 0 & 0 \\
\hline AK & 6 & 4 \\
\hline AS & 7 & 6 \\
\hline $\mathrm{NH}$ & 2 & 2 \\
\hline $\mathrm{OZ}$ & 1 & 1 \\
\hline $\mathrm{AV}$ & $1(0.59) 10(0.02) 20(0.27) 32(0.03) 39(0.05)$ & $1(0.65) 10(0.00) 20(0.26) 32(0.03) 39(0.05)$ \\
\hline$C X$ & 2 & 2 \\
\hline $\mathrm{Cl}$ & $7(0.05) 14(0.05) 21(0.76) 35(0.06)$ & $7(0.05) 14(0.04) 21(0.85) 35(0.06)$ \\
\hline $\mathrm{MU}$ & $10(1.15) 20(0.02) 32(0.18) 35(0.34)$ & $7(0.02) \quad 10(0.43) 19(0.16) 32(0.12) 35(0.27)$ \\
\hline $\mathrm{CZ}$ & $10(1.99) 27(0.59) 32(0.07) 35(0.21)$ & $5(0.05) 10(0.51) 19(0.32) 35(0.12)$ \\
\hline $\mathrm{CM}$ & $9(0.30) 20(0.05) 21(0.18) 27(0.43)$ & $9(0.27) 21(0.24) 27(0.47) 35(0.01)$ \\
\hline $\mathrm{DL}$ & 0 & 4 \\
\hline $\mathrm{U} 2$ & 12 & 9 \\
\hline LY & 5 & 5 \\
\hline $\mathrm{BR}$ & $14(0.17) 21(0.74) 35(0.04)$ & $14(0.17) 21(0.80) 35(0.03)$ \\
\hline $\mathrm{AY}$ & 0 & 0 \\
\hline GA & $1(0.41) 20(0.32) 31(0.09) 39(0.02)$ & $1(0.60) 20(0.30) 31(0.06) 39(0.03)$ \\
\hline G3 & $1(0.03) 3(0.17) 9(0.46) 20(0.23)$ & $1(0.25) 9(0.52) 20(0.22) 39(0.00)$ \\
\hline $\mathrm{HU}$ & 0 & 0 \\
\hline HA & 7 & 3 \\
\hline QJ & $7(0.01) 20(0.09) 21(0.14) 27(0.61) 35(0.09)$ & $7(0.01) 20(0.10) 21(0.22) 27(0.59) 35(0.08)$ \\
\hline B6 & $10(0.77) 20(0.18) 35(0.12)$ & $10(0.71) 19(0.01) 20(0.14) 35(0.13)$ \\
\hline $\mathrm{KE}$ & $6(0.24) 7(0.04) 11(0.05) 12(0.51) 38(0.13)$ & $6(0.23) 7(0.03) 11(0.05) 12(0.56) 38(0.12)$ \\
\hline LA & 2 & 2 \\
\hline LH & 6 & 3 \\
\hline D8 & 0 & 0 \\
\hline QF & 0 & 0 \\
\hline$F R$ & 8 & 10 \\
\hline SK & $1(0.56) 11(0.05) 20(0.26) 32(0.03)$ & $1(0.58) 11(0.12) 20(0.18) 39(0.12)$ \\
\hline SC & $1(0.53) 9(0.28) 20(0.06) 39(0.05)$ & $1(0.52) 9(0.36) 20(0.01) 39(0.10)$ \\
\hline SQ & 1 & 1 \\
\hline 00 & 5 & 6 \\
\hline WN & $10(1.05) 20(1.50) 32(0.09) 39(0.35)$ & 0 \\
\hline TG & 0 & 0 \\
\hline TK & $5(0.46) 9(0.72) 27(1.05) 35(0.13)$ & $5(0.61) 10(0.09) 19(0.01) 35(0.29)$ \\
\hline UA & $6(0.20) 7(0.17) \quad 10(0.34) 27(10.84)$ & 0 \\
\hline VA & $1(0.68) 20(0.19) 31(0.03) 32(0.02) 39(0.02)$ & $1(0.75) 20(0.17) 31(0.04) 32(0.02) 39(0.02)$ \\
\hline WS & $9(0.18) 20(0.24) 21(0.19) 27(0.33)$ & $20(0.11) 21(0.26) 27(0.56) 35(0.07)$ \\
\hline
\end{tabular}


EK 3 - Havayollarının Mevcut Değerleri ve Etkinliğe Ulaşabilmeleri Için Gerekli Olan Hedef Çıktı Değişkenleri (CCR Modeli 2010)

\begin{tabular}{|c|c|c|c|c|c|c|c|c|}
\hline & \multicolumn{3}{|c|}{ RPK } & \multicolumn{2}{c|}{ Yolcu Sayıs } & \multicolumn{2}{c|}{ Toplam Gelir } \\
\hline & Mevcut & Hedef & Mevcut & Hedef & Mevcut & Hedef & Mevcut & Hedef \\
\hline EI & 14220000 & 14725505 & 78 & 79 & 9700000 & 10901068 & 1605000 & 1625245 \\
\hline SU & 39172000 & 43022259 & 77 & 84.5 & 14100000 & 22862360 & 4308000 & 4731438 \\
\hline AM & 18632000 & 19328102 & 77 & 79 & 11600000 & 12033382 & 2220000 & 2302940 \\
\hline AC & 83485000 & 87733963 & 82 & 92 & 32000000 & 46578935 & 10428000 & 10958732 \\
\hline CA & 86194000 & 89249657 & 80 & 95 & 46200000 & 58962354 & 12203000 & 12635607 \\
\hline AF/KL & 125165000 & 125535456 & 81 & 81.5 & 47000000 & 52172624 & 31276000 & 31368568 \\
\hline AS & 32750000 & 34142280 & 83 & 86.5 & 16500000 & 22510168 & 3832000 & 3994907 \\
\hline CI & 32246000 & 33561817 & 81 & 84 & 10500000 & 13426993 & 4401000 & 4580585 \\
\hline MU & 93153000 & 99649815 & 78 & 95 & 64900000 & 69426352 & 11089000 & 11862385 \\
\hline CZ & 111328000 & 122094713 & 79 & 93 & 76500000 & 84944071 & 11317000 & 12411485 \\
\hline DL & 310876000 & 322717187 & 83 & 94 & 162600000 & 190207360 & 3175500 & 32964539 \\
\hline BR & 23625000 & 24718919 & 80 & 83 & 6400000 & 11840424 & 3327000 & 3481051 \\
\hline AY & 19222000 & 21035144 & 77 & 84 & 7100000 & 12710696 & 2671000 & 2922946 \\
\hline GA & 20464000 & 25583454 & 69 & 86 & 12800000 & 18388895 & 2027000 & 2534092 \\
\hline QJ & 26972000 & 29260433 & 79 & 86 & 14700000 & 17666974 & 2844000 & 3085298 \\
\hline B6 & 45511000 & 48568113 & 81 & 86 & 24300000 & 39313785 & 3779000 & 4032847 \\
\hline WN & 125604000 & 138263387 & 79 & 94 & 88200000 & 108524534 & 12104000 & 13323939 \\
\hline TG & 55676000 & 56082728 & 74 & 92 & 18200000 & 23632582 & 5822000 & 5972437 \\
\hline TK & 47950000 & 55023319 & 74 & 85 & 29100000 & 33392671 & 5567000 & 6388213 \\
\hline VA & 26895000 & 28821653 & 79 & 85 & 18600000 & 19932431 & 2625000 & 2813044 \\
\hline WS & 25127000 & 26764688 & 80 & 85 & 15200000 & 17493072 & 2577000 & 2744959 \\
\hline
\end{tabular}

EK 4 - Havayollarının Mevcut Değerleri ve Etkinliğe Ulaşabilmeleri Iç̧in Gerekli Olan Hedef Çıktı Değişkenleri (BCC Modeli 2010)

\begin{tabular}{|c|c|c|c|c|c|c|c|l|}
\hline \multirow{2}{*}{} & \multicolumn{3}{|c}{ RPK } & \multicolumn{2}{c|}{ Doluluk Oranı } & \multicolumn{2}{c|}{ Yolcu SayıII } & \multicolumn{2}{c|}{ Toplam Gelir } \\
\cline { 2 - 9 } & Mevcut & Hedef & Mevcut & Hedef & Mevcut & Hedef & Mevcut & Hedef \\
\hline SU & 39172000 & 43019511 & 77 & 85 & 14100000 & 22850470 & 4308000 & 4731135 \\
\hline AM & 18632000 & 19302506 & 77 & 82.5 & 11600000 & 11998195 & 2220000 & 2296206 \\
\hline AC & 83485000 & 86962976 & 82 & 85.5 & 32000000 & 45979293 & 10428000 & 10862429 \\
\hline AS & 32750000 & 34154372 & 83 & 86 & 16500000 & 22616667 & 3832000 & 3979259 \\
\hline CI & 32246000 & 33546295 & 81 & 85.5 & 10500000 & 13517989 & 4401000 & 4578466 \\
\hline MU & 93153000 & 97375634 & 78 & 81.5 & 64900000 & 67841923 & 11089000 & 11591665 \\
\hline CZ & 111328000 & 117091001 & 79 & 83.5 & 76500000 & 80460096 & 11317000 & 11902835 \\
\hline BR & 23625000 & 24636630 & 80 & 85.2 & 6400000 & 11782398 & 3327000 & 3469463 \\
\hline AY & 19222000 & 21030316 & 77 & 84.5 & 7100000 & 12709266 & 2671000 & 2922275 \\
\hline GA & 20464000 & 25744773 & 69 & 85.6 & 12800000 & 18446741 & 2027000 & 2515975 \\
\hline QJ & 26972000 & 29260189 & 79 & 86 & 14700000 & 17665917 & 2844000 & 3085272 \\
\hline B6 & 45511000 & 48377202 & 81 & 86 & 24300000 & 39237861 & 3779000 & 4016994 \\
\hline WN & 125604000 & 131843486 & 79 & 83.5 & 88200000 & 89178203 & 12104000 & 12238242 \\
\hline TG & 55676000 & 56035135 & 74 & 79.5 & 18200000 & 23207137 & 5822000 & 5968850 \\
\hline TK & 47950000 & 54851855 & 74 & 85 & 29100000 & 33288612 & 5567000 & 6368306 \\
\hline VA & 26895000 & 28821246 & 79 & 85 & 18600000 & 19932150 & 2625000 & 2813005 \\
\hline WS & 25127000 & 26759565 & 80 & 86 & 15200000 & 17460786 & 2577000 & 2744434 \\
\hline
\end{tabular}


Eskişehir Osmangazi Üniversitesi IißBF Dergisi 